\title{
Efeitos de competição, gastos de campanha e fragmentação eleitoral sobre comparecimento e votos válidos nas eleições municipais brasileiras em 2012
}

Cíntia Pinheiro Ribeiro de Souza ${ }^{1}$ (i)

\begin{abstract}
Este artigo investiga fatores associados aos níveis de comparecimento eleitoral, em especial, variáveis políticas contextuais. $O$ argumento é de que, com o enfraquecimento de condicionantes duradouros, como os sociodemográficos e os sociopsicológicos, devemos atentar ao efeito de curto prazo da conjuntura sobre a participação eleitoral. $O$ estudo desse efeito ainda é incipiente no Brasil e na América Latina. A expectativa inicial era de que competição, gastos de campanha e fragmentação estivessem associados positivamente com a participação eleitoral agregada. Essa hipótese foi testada por meio de modelos lineares multivariados nas eleições para prefeito de 2012. Os resultados confirmam essa hipótese em relação à competição e aos gastos de campanha, com mais força ainda sobre os votos válidos se comparados ao comparecimento em si. Porém, os resultados apontam um efeito negativo da fragmentação.
\end{abstract}

Palavras-chave: comparecimento eleitoral; competição eleitoral; gastos de campanha; fragmentação eleitoral; Brasil

\section{Introdução}

A literatura sobre comparecimento eleitoral aponta que existem basicamente três vertentes de explicações para esse fenômeno. Uma delas relaciona variáveis sociodemográficas, outra, variáveis sociopsicológicas e, a última, variáveis conjunturais ou institucionais. As duas primeiras vertentes têm em comum o fato de que explicam melhor variações de longo prazo no comparecimento porque se baseiam em aspectos mais perenes como o contexto sociodemográfico e as atitudes dos eleitores. A terceira vertente esclarece melhor as variações de curto prazo pois se pauta por cálculos individuais acerca de custos e benefícios de participar.

O propósito deste artigo é justamente dar atenção a esse último fator explicativo que tem a ver com uma perspectiva racional de curto prazo para o fenômeno do

\footnotetext{
${ }^{1}$ Universidade Federal de Santa Catarina - Centro de Filosofia e Ciências Humanas (CFH), Florianópolis (SC), Brasil. E-mail: <cprsouza@gmail.com>.

2 Agradeço aos integrantes do projeto Procad UFSC-UEM-Unesp Araraquara intitulado "Mudanças e permanências nos padrões de participação política no Brasil", aos colegas do Núcleo de Estudos em Comportamento e Instituições Políticas da UFSC e aos pareceristas anônimos pelos comentários que me ajudaram a melhorar versões anteriores deste artigo.
} 
comparecimento eleitoral. A literatura tem identificado o enfraquecimento dos condicionantes mais permanentes, o que abriria ainda mais oportunidade para fatores de curto prazo afetarem a decisão dos eleitores de comparecer e votar nas eleições. Ademais, a influência de variáveis conjunturais é um ponto pouco explorado no Brasil em relação ao comparecimento, especialmente se pensarmos em variáveis ligadas ao contexto da campanha política, pois não se encontram trabalhos que tenham se dedicado a testar o impacto dessas variáveis mais detidamente ${ }^{3}$. Alguém pode objetar que, diante do voto obrigatório, não seria esperada outra coisa porque o que importam são as abstenções e os votos inválidos. Entretanto, mostro com este artigo que existem variações importantes no comparecimento e nos votos válidos nas eleições, a despeito de médias altas de comparecimento por conta de nossa regra eleitoral.

A hipótese que guiou este artigo foi a de que elementos de conjuntura política como a competição, a mobilização das elites e a fragmentação influenciam a decisão dos eleitores de irem até as urnas e votarem em um candidato. Para investigar essa hipótese, testei o impacto dessas variáveis conjunturais controladas por variáveis sociodemográficas para verificar como elas se associam aos percentuais de comparecimento e de votos válidos em eleições majoritárias em 2012. Os resultados obtidos confirmam a expectativa inicial de que os fatores de curto prazo importam para os níveis de participação do eleitorado medidos tanto pelo comparecimento quanto pelos votos válidos.

Este artigo está dividido em quatro partes principais, além desta breve introdução e das considerações finais. Na seção "Os determinantes do comparecimento eleitoral", apresento um panorama da literatura que trata do comparecimento eleitoral no mundo e no Brasil. Em seguida, na terceira seção, "A importância do contexto da competição política para o comparecimento eleitoral", discuto de forma mais específica os mecanismos causais esperados entre as variáveis de conjuntura política e o fenômeno do comparecimento. Na quarta seção, "Comparecimento eleitoral nas eleições para prefeito em 2012", exponho e justifico minha estratégia de análise, os dados utilizados e alguns dos desafios empíricos enfrentados. Na quinta seção, "Qual o impacto do contexto da competição política no comparecimento eleitoral das eleições municipais?", apresento e discuto os resultados dos testes estatísticos. Por fim, ofereço algumas considerações finais acerca desse exercício exploratório do impacto das variáveis de conjuntura política sobre o comparecimento eleitoral para o caso brasileiro.

\footnotetext{
3 Entre os estudos que desenvolveram essa questão no Brasil estão os trabalhos de Rennó (2006, 2007), que, baseados em dados individuais obtidos através de pesquisa de painel, apontam que os eleitores enfrentam dificuldade de obter informação sobre candidatos quando a concorrência é fragmentada, embora essa dificuldade seja amenizada pela informação gerada pela campanha, e que esse tipo de informação específica tem um impacto positivo na disposição de votar em um candidato e votar partidariamente. Entretanto, nesses estudos, apenas a disposição para realizar um voto em um candidato é considerada, diferentemente deste artigo, que avalia diferenças entre o ato de comparecer e o ato de depositar um voto válido.
} 


\section{Os determinantes do comparecimento eleitoral}

O tópico do comparecimento eleitoral tem sido estudado recentemente pela literatura sob a ótica do fenômeno do desencanto com as instituições políticas tradicionais, visualizado, entre outras medidas, pela queda na taxa de comparecimento através do tempo nas democracias ocidentais. A teoria da modernização que vem sendo gestada desde a década de 1970 ofereceu uma explicação para essa tendência declinante (Inglehart e Welzel, 2009; Wattenberg, 2000). Por essa perspectiva, a interação entre desenvolvimento econômico e tradições culturais produziu mudanças de valores de maneira que a democracia foi um resultado institucional lógico desse desenvolvimento. Entretanto, essas mudanças também teriam trazido a ascensão de valores de autoexpressão que desembocaram na busca por maior autonomia por parte dos indivíduos, envolvendo inclusive a disseminação de ações cívicas a desafiar as elites políticas, como abaixo-assinados, boicotes, manifestações, entre outras ações.

Especificamente no que diz respeito ao comparecimento, Wattenberg (2000) indicou que transformações no nível micro podem levar a transformações nos partidos porque eleitores mais educados e afluentes passam a questionar as hierarquias e não se guiam tão facilmente pelo atalho de informação conferido pelos partidos. A erosão do modelo de política baseado na mobilização de grupos por conta da crescente mobilidade social e geográfica enfraqueceu as relações entre indivíduos e comunidades, assim como o voto baseado em clivagens tradicionais (classe, religião). Ademais, associou-se a esses desenvolvimentos a emergência do pós-materialismo, que incentivou a busca de participação direta e fora dos canais tradicionais de representação.

Além do desencanto com as instituições políticas tradicionais, outra chave interpretativa para o fenômeno do comparecimento eleitoral tratou da exclusão ou da desigualdade no comparecimento. É nessa linha que Gallego (2015) desenvolveu seu estudo comparado sobre desigualdade na participação política entre os mais e os menos educados. A autora testou hipóteses de que determinadas instituições ou contextos promoveriam aumento ou diminuição da desigualdade na participação eleitoral. Entre os fatores que poderiam promover aumento na desigualdade, estariam a dificuldade ou a complexidade da cédula e dos procedimentos de votação de acordo com o sistema eleitoral adotado, eleições que resultam em governos de coalizão e a desigualdade de renda. Entre as variáveis que poderiam promover diminuição na desigualdade, estariam a predominância de sistemas de mídia orientados para o público, a força e a densidade de organizações sindicais e a renda. Em boa parte, os achados da autora, baseados em experimentos e modelos multivariados que usam dados de pesquisas de opinião e agregados, confirmam essas hipóteses.

Historicamente, de acordo com Caldeira, Patterson e Markko (1985), o comparecimento foi tratado de forma determinista na literatura dos anos 1940, como função de características sociodemográficas nas quais se incluíam as diversas variáveis 
socioeconômicas agregadas como educação, raça, renda, idade. Segundo os autores, essa vertente sociodemográfica é a maneira mais antiga e influente de explicar o comparecimento eleitoral. Desde os anos 1950 e, especialmente, a partir do estudo de Campbell et al. (1960), atitudes sociais e psicológicas capturadas por pesquisas de opinião, como dever cívico, percepção sobre eficácia política, compromisso partidário e interesse pela política, começaram a se destacar como variáveis explicativas. Na década de 1970 e 1980, os estudos retomaram o modelo downsiano desenvolvendo uma vertente de teoria racional para explicar o fenômeno do comparecimento. O cálculo individual em torno de custos e benefícios acerca do retorno esperado do voto passou a se destacar, assim como determinadas variáveis explicativas, dentre as quais se incluíam fatores institucionais, como restrições legais sofridas pelos eleitores para se registrar, condições econômicas adversas e mobilização política (competição política e gastos de campanha, principalmente), sendo essa última uma das linhas explicativas menos desenvolvidas nos estudos.

Cada um desses vieses, seja sociodemográfico, sociopsicológico ou racional, possui forças e fraquezas. Por um lado, os dois primeiros, ao se basearem em características fixas ou de mudança lenta, permitem explicações para tendências no comparecimento eleitoral de longo prazo, mas encontram dificuldade para explicar variações de curto prazo. Até mesmo as atitudes políticas, que sofrem flutuações de curto prazo em função da conjuntura, tendem a se alterar de maneira mais lenta pois se baseiam em fatores como crenças, identidades e socialização política no seio familiar. Por outro lado, o viés racional se adapta melhor para explicar as variações de curto prazo. Não por acaso, muitos trabalhos combinam variáveis para refletir esses diferentes vieses de maneira a aumentar seu poder de explicação sobre o fenômeno.

Geys (2006) analisou 83 estudos para explicar o comparecimento, baseados em dados agregados, avaliando quais foram as variáveis usadas, as teorias que as justificavam e a taxa de sucesso dessas variáveis, assim como o nível do impacto estimado de cada uma delas em explicar o comparecimento. Em relação às variáveis socioeconômicas, aquelas que se saíram bem-sucedidas nos testes foram o tamanho da população e a estabilidade da população. O efeito esperado do tamanho da população era negativo, uma vez que, quanto mais eleitores, menos decisivo é o voto de um único eleitor para o resultado das eleições. Já o efeito esperado da estabilidade da população era positivo, pois, quanto mais estável é a condição do eleitor em seu distrito (ou seja, porcentagem significativa de habitantes que são proprietários de uma casa ou a porcentagem pequena de pessoas que se mudam para outro lugar), maior conhecimento ele acumula sobre seu contexto, o que acaba por diminuir os custos de escolha. Outras variáveis sociodemográficas presentes nos estudos mas que não alcançaram resultados tão consistentes foram densidade da população (efeito esperado seria negativo porque essa característica favoreceria o individualismo), homogeneidade da população (efeito esperado seria positivo porque essa característica facilitaria o exercício da pressão social de grupos) 
e comparecimento anterior (efeito esperado seria positivo porque o comparecimento anterior poderia ser interpretado como um hábito de votar).

Já em relação às variáveis de conjuntura política, o autor apontou que somente a margem de vitória, a variável mais frequente nos estudos, presente em 52 dos 83 analisados, e os gastos de campanha foram bem-sucedidos nos testes, de maneira que os resultados sobre fragmentação política foram inconclusivos. Quanto menor a margem de vitória e maiores os gastos de campanha, maior comparecimento é esperado porque o voto de um eleitor se aproxima mais de ser pivotal e mais informação circula nas campanhas, de modo que os eleitores se tornam mais capazes de diferenciar os candidatos e mais atentos sobre as eleições e os resultados delas. No entanto, cabe a ressalva de que, embora a margem de vitória seja mensurada ex post muitas vezes, ela se saiu melhor nos testes quando foi medida ex ante, por meio de pesquisas de intenção de voto.

Por fim, em relação às variáveis institucionais, os resultados encontrados por Geys (2006) apontaram que sistemas proporcionais geram maior comparecimento, assim como o voto obrigatório, eleições coincidentes e regras amigáveis de registro dos eleitores. Era esperado que sistemas proporcionais gerassem maior comparecimento porque, com mais candidatos, haveria uma chance maior de os eleitores se sentirem representados por algum deles. As eleições coincidentes e as regras amigáveis de registro dos eleitores diminuem os custos de comparecer, enquanto o voto obrigatório funciona como um incentivo ao comparecimento, especialmente quando há punições significativas em caso de abstenção.

Mais recentemente, Fisher (2018) fez uma revisão bibliográfica de estudos que investigam o efeito das campanhas sobre o comparecimento e a escolha do eleitor. Além de destacar os achados tradicionais que associam maiores gastos com comparecimento e votos, o autor chama a atenção para os estudos que deram um passo à frente e analisaram quais tipos de campanhas têm maior efetividade sobre os resultados eleitorais, algo que está além do escopo deste artigo. De todo modo, o autor ressalta que eleições apertadas ou que apresentam uma probabilidade maior de mudar o status quo são fatores que provavelmente influenciarão a efetividade eleitoral das próprias campanhas.

No Brasil, segundo Nicolau (2002), embora o comparecimento seja obrigatório para pessoas com 18 anos ou mais desde 1934, foi apenas em 1945 que mais de $10 \%$ da população compareceu para votar. Contudo, de 1889 a 1984, vigorou a exigência de que os eleitores deveriam saber ler e escrever, o que excluiu boa parte da população brasileira do universo de eleitores no período.

De toda forma, a obrigatoriedade do voto fez com que o fenômeno de interesse nos estudos brasileiros fosse o ato contrário de comparecer, ou seja, o ato de se abster ou de votar inválido (branco ou nulo). De acordo com Silva (2016), a literatura brasileira sobre alienação eleitoral teria se desenvolvido mais significativamente desde os anos 1970 . Inicialmente, os autores que buscaram compreender o sistema político-partidário brasileiro a partir de 1945 notaram um crescimento da taxa de votos inválidos no período até 1966, e problematizaram a questão dos votos brancos e nulos como expressão de falta de 
interesse e motivação dos eleitores em relação ao sistema eleitoral (Schwartzman, 1975, p. 155 e segs.). Apesar disso, essa visão sofreu críticas por desconsiderar explicações alternativas para o fenômeno dos votos inválidos - entre elas, os diferentes padrões desses votos nas eleições executivas e legislativas, que poderiam significar, nas primeiras, a não incorporação do eleitorado das pequenas cidades e do interior à participação eleitoral e, nas segundas, a automarginalização do eleitorado urbano das capitais e das grandes cidades - e, principalmente, por inferir explicações para o comportamento individual a partir de dados agregados (Campello de Souza, 1976, p. 164 e segs.).

Nos anos 1980, o trabalho de Santos buscou dar uma explicação em termos de teoria racional para o fenômeno chamado de alienação eleitoral, referente a abstenções, votos brancos e nulos (Santos, 1987, 2003). Nessa chave explicativa, o que se destacou foi o cálculo do eleitor em relação ao retorno esperado de seu voto. O autor mediu as taxas de alienação de 1945 a 1982 e observou movimentos ondulatórios destas. Na interpretação do autor, por uma parte, os movimentos ascendentes coincidiram com momentos de aumento da incerteza quanto às reais consequências políticas dos resultados das eleições, dando como exemplo a deposição de Getúlio Vargas e o contexto de radicalização de 1962; por outra parte, os movimentos decrescentes de alienação eleitoral teriam se ajustado a períodos de maior estabilidade e confiança, como o do governo Juscelino Kubitschek.

Não obstante, críticas à tese de Santos surgiram nos trabalhos de Lima Júnior por agregar manifestações eleitorais diferentes - a abstenção, o voto em branco e o voto nulo - cujos fatores determinantes seriam distintos conquanto fossem ações de significados distintos, importando, dessa maneira, decompor a alienação entre a abstenção, de um lado, e os votos brancos e nulos, de outro (Lima Júnior, 1993, p. 100 e segs.). Os resultados obtidos por Lima Júnior apontavam que abstenções eram impactadas negativamente pela urbanização e positivamente pela extensão territorial e pelo analfabetismo, enquanto votos brancos e nulos eram impactados negativamente pela extensão territorial e, positivamente, pelo analfabetismo (p. 105 e segs.).

Outras críticas também emergiram no sentido de problematizar o descompasso entre o recadastramento de eleitores e a maneira pela qual as abstenções são medidas, levando em conta o número de eleitores aptos registrados junto à Justiça Eleitoral, que estaria, em função daquele descompasso, desatualizado e, por conseguinte, o número de abstenções seria superestimado (Nicolau, 2002). Além disso, outro ponto criticado foi a interpretação dos votos nulos e brancos na medida em que as interpretações mais influentes para o fenômeno do comparecimento desconsideraram a variação das cédulas ou das formas de votar e a decorrente variação da dificuldade de realizar esse exercício pelos eleitores ao longo do tempo (Nicolau, 2004; Zucco e Nicolau, 2016).

Houve predomínio da análise de dados agregados de contexto sociodemográfico na literatura brasileira sobre alienação eleitoral, embora trabalhos recentes tenham explorado dados individuais, inclusive utilizando-os em análise multinível, como é o caso dos estudos de Ribeiro, Borba e Silva (2015) em pesquisa comparada sobre América Latina 
e de Silva (2016), que também comparou países da América Latina, mas dedicou um capítulo de seu estudo apenas ao caso brasileiro. Os resultados encontrados por Ribeiro, Borba e Silva (2015) ressaltam o efeito positivo da urbanização, da idade, da escolaridade, da obrigatoriedade do voto e do sentimento em favor da democracia para o comparecimento e o efeito negativo da elevação do PIB e do bicameralismo. Os achados de Silva (2016) para o Brasil apontam que as abstenções se relacionam com a baixa escolaridade e os sentimentos de falta de eficácia política e de indiferença, ao passo que votos brancos e nulos são expressões de protesto de um eleitor que possui recursos individuais, mas é afastado da política. Inclusive, para a América Latina, o autor testou o efeito das variáveis conjunturais número efetivo de partidos e eleições apertadas sobre as abstenções, encontrando o resultado de que essa última variável traria uma redução na probabilidade de o eleitor se abster na ordem de 37\% (Silva, 2016, p. 103) ${ }^{4}$. Entretanto, nenhuma dessas variáveis foi incluída nos testes desenhados exclusivamente para o caso brasileiro.

Diante dessa lacuna, meu objetivo é explorar a associação das variáveis de conjuntura, especialmente margem de vitória, gastos de campanha e fragmentação partidária, com os níveis de comparecimento eleitoral no Brasil. Na próxima seção, discuto a importância do contexto da competição política para o comparecimento eleitoral e os mecanismos causais que os associam.

\section{A importância do contexto da competição política para o comparecimento eleitoral}

Nesta seção, meu objetivo é justificar a relevância das variáveis do contexto da competição política para o estudo do comparecimento eleitoral. A base para essa justificativa se assenta no viés racional das teorias sobre as causas que levam as pessoas a votar. A teoria de escolha racional para o voto propõe que potenciais eleitores pesam custos e benefícios acerca do retorno esperado de seu voto quando decidem se vale a pena comparecer ou não (Downs, 2013). Nesse cálculo, a percepção dos eleitores sobre a efetividade de seu voto e a capacidade de influenciar as políticas públicas se destacam como benefícios importantes, assim como determinadas regras eleitorais e fatores conjunturais que podem elevar ou diminuir os custos da participação dos eleitores.

Especificamente no tocante à percepção dos eleitores sobre a efetividade de seu voto, a hipótese predominante na literatura é de que maior competição influencia a percepção dos eleitores de que seu voto seria mais decisivo e de que, por isso, eles estariam mais dispostos a comparecer às urnas (Blais, 2010). O indicador usado mais frequentemente para medir a competição tem sido a diferença de (intenção de) votos entre o primeiro e o segundo colocados numa disputa dividida pelo total de votos no distrito,

\footnotetext{
4 Silva (2016) adotou a definição de disputa apertada como aquela cuja diferença entre o primeiro e o segundo colocados tivesse sido inferior a 5 pontos percentuais.
} 
número esse conhecido como margem de vitória (Geys, 2006). Dito de outro modo, quanto menor a diferença de (intenção de) votos do primeiro para o segundo colocado, maior a percepção do eleitor que seu ato de ir às urnas pode ser pivotal para o resultado das eleições. Dessa maneira, deveríamos observar uma relação negativa entre margem de vitória e comparecimento. Diversos estudos mostraram evidências empíricas dessa relação: Settle e Abrams (1976), para as eleições presidenciais norte-americanas; Cox e Munger (1989), para as eleições legislativas norte-americanas; Ansolabehere et al. (1994), para eleições ao Senado norte-americano; Pattie e Johnston (1998), para as eleições parlamentares britânicas; Francia e Herrnson (2004), para as eleições legislativas estaduais norte-americanas ${ }^{5}$. Todavia, outros autores não encontraram resultados tão consistentes. Hogan (1999) encontrou sinais esperados e significativos estatisticamente quando a margem de vitória era medida em relação à eleição anterior e apenas nos modelos parciais ao estudar as eleições legislativas estaduais dos Estados Unidos. Jackson (1996) encontrou o sinal esperado negativo para a relação entre closeness e comparecimento ao analisar as eleições legislativas norte-americanas, mas os resultados não foram estatisticamente significantes ${ }^{6}$. Holbrook e McClurg (2005) encontraram sinais na direção esperada, mas não estatisticamente significantes para as eleições presidenciais nos Estados Unidos. Por sua vez, Matsukaka e Palda (1999), ao analisarem as eleições parlamentares canadenses, também não encontraram coeficientes significantes.

Não há unanimidade sobre a maneira de operacionalizar a margem de vitória. A forma mais comum observada nos trabalhos analisados pelo presente artigo é a diferença percentual de votos entre o primeiro e o segundo colocados (Settle e Abrams, 1976; Hogan, 1999; Francia e Herrnson, 2004; Holbrook e McClurg, 2005), porém há autores que a operacionalizam como o quadrado dessa diferença (Ansolabehere et al., 1994). Outras formas de operacionalizar a margem de vitória alteram ligeiramente a maneira mais comumente usada, calculando a marginalidade como 100 menos a porcentagem da maioria do partido vencedor sobre o segundo colocado, que, então, aumenta conforme a cadeira se torna mais marginal (Pattie e Johnston, 1998), ou calculando a proporção da margem de vitória em relação ao total de votos combinados do primeiro e do segundo colocados somente e não em relação ao total de votos do distrito (Matsukaka e Palda, 1999)7 . Outras

\footnotetext{
5 Ansolabehere et al. (1994) mediram a competitividade (que chamaram de closeness, embora se aproximasse mais da ideia de margem de vitória em termos percentuais) como o quadrado da diferença percentual entre o primeiro e o segundo colocados. Seus achados são no sentido esperado (relação negativa entre margem de vitória e comparecimento), porém não alcançaram níveis de significância estatística, talvez pelo número reduzido de casos $(\mathrm{N}=34)$. O trabalho de Cox e Munger (1989) é o único aqui analisado que testa o efeito das variáveis margem de vitória (percentual) e closeness (absoluta) sobre o comparecimento em diferentes modelos. Nesses últimos, ambas as variáveis alcançaram níveis convencionais de significância estatística.

6 Closeness foi operacionalizada por Jackson (1996) como a diferença entre os votos do primeiro e do segundo colocados e seu termo quadrático.

7 Pattie e Johnston (1998) definem margem (ou marginality) de modo ligeiramente diferente dos outros autores: 100 menos a porcentagem da maioria do partido vencedor sobre o segundo colocado, que, então, aumenta conforme a cadeira se torna mais marginal. Por essa razão, para esses autores, a relação esperada entre marginality e comparecimento é positiva, ou seja, quanto mais marginal é a disputa, menor a distância
} 
EFEITOS DE COMPETIÇÃO, GASTOS DE CAMPANHA E FRAGMENTAÇÃO ELEITORAL

exceções dizem respeito aos autores que criticaram o uso da margem de vitória como variável independente em estudos sobre comparecimento uma vez que o total de votos faz parte do denominador da primeira e do numerador da segunda. A alternativa proposta foi usar a diferença absoluta entre os votos do primeiro e do segundo colocados juntamente com o termo quadrático dessa diferença (para o controle de retornos marginais decrescentes) (Cox e Munger, 1989; Jackson, 1996). O efeito esperado de closeness, assim como a margem de vitória, é negativo. Contudo, cabe a ressalva de que a diferença absoluta torna a medida pouco comparável entre distritos de tamanhos diferentes e que os autores que defendiam tal alternativa analisavam eleições para a House of Representatives norte-americana que ocorrem em distritos relativamente equivalentes, de tamanho definido conforme o censo realizado a cada 10 anos $^{8}$.

Entretanto, não são apenas as inconsistências no plano empírico que põem em dúvida a importância da competição política em termos de margem de vitória para o comparecimento eleitoral. No plano teórico, se o voto instrumental for levado às últimas consequências, a estratégia ótima para os eleitores seria se abster naquilo que ficou conhecido como o paradoxo do não voto ou da não participação eleitoral (Downs, 2013). Isso porque a probabilidade de um único voto ser decisivo é muito pequena, mesmo em eleições muito disputadas, então o valor instrumental do voto nessas eleições também seria pequeno. Figueiredo (2008) propôs que a solução para esse paradoxo está no fato de que, se todos os eleitores decidirem não participar, a eficiência do voto de um eleitor cresce e, no limite, pode decidir sozinho a eleição. Porém, o autor ressalta que, como os demais eleitores isoladamente vivem o mesmo dilema, todos, pela mesma antecipação com vistas a maximizar a utilidade esperada de seu ato, tendem a participar, pois não participar aumenta a eficiência dos votos dos demais que decidirem participar.

Cox e Munger (1989) propuseram a hipótese de que o efeito da competição não se daria diretamente sobre o eleitorado, mas mediado pela atividade das elites políticas que, em face de eleições apertadas, buscariam ativar e instigar os eleitores a comparecer. Para eles, os gastos de campanha poderiam ser uma proxy da atividade das elites e essa tem sido a variável mais comumente usada para medir o efeito dessas atividades. Os autores consideraram pelo menos três explicações para que haja mais dinheiro empregado nas eleições apertadas: porque os apoiadores consideram que suas doações têm mais chances de afetar o resultado, então doam mais; porque os próprios candidatos estarão fazendo mais promessas para seus apoiadores (vendendo acesso) em troca de mais recursos; e porque os candidatos valorizam cada centavo em eleições disputadas e têm mais disposição de gastar nelas (Cox e Munger, 1989, p. 218-219). Além de proxy para a atividade das elites, os gastos de campanha também foram usados como controle para a

entre os dois primeiros colocados e maior o incentivo para comparecer. Aqui, marginal se refere à suscetibilidade de que qualquer pequena alteração possa fazer diferença para o resultado final da eleição.

${ }^{8}$ Ver: US Census Bureau. Disponível em: <https://www.census.gov/prod/cen2010/briefs/c2010br-08.pdf>. Acesso em: 12 fev. 2018. 
influência da informação sobre o comparecimento. A hipótese testada por Settle e Abrams (1976) foi a de que aumentos na disponibilidade de informação sobre os candidatos geram aumento da probabilidade de as campanhas capturarem o interesse dos eleitores, levandoos às urnas. Os autores utilizaram os gastos de campanha como um indicador para a influência da informação porque defendiam que a disponibilidade de informação seja, provavelmente, função direta dos gastos de campanha: mais gastos de campanha geram mais informação, que é transmitida para os eleitores ajudando-os a diferenciar os candidatos. Em resumo, o efeito esperado dos gastos de campanha sobre o comparecimento seria positivo9 ${ }^{9}$. A maioria dos estudos analisados por Geys (2006) confirmou essa hipótese, assim como a maior parte dos estudos aqui analisados (Settle e Abrams, 1976; Caldeira, Patterson e Markko, 1985; Jackson, 1996; Hogan, 1999; Matsukaka e Palda, 1999; Francia e Herrnson, 2004; Holbrook e McClurg, 2005) ${ }^{10}$. Alguns estudos confirmam parcialmente 0 efeito dos gastos de campanha sobre o comparecimento, por exemplo, quando a variável competição partidária é excluída (Dawson e Zinser, 1976), quando a competição é medida através de closeness e não através de margem de vitória (Cox e Munger, 1989) ou para apenas o gasto de alguns partidos, no caso, dos trabalhistas britânicos (Pattie e Johnston, 1998).

De maneira semelhante ao que acontece com a variável margem de vitória, há diversas operacionalizações para a variável gastos de campanha nos estudos analisados no presente artigo. As formas mais frequentes são o gasto total per capita no distrito (Settle e Abrams, 1976; Matsukaka e Palda, 1999; Francia e Herrnson, 2004), seguido de gasto total per capita no distrito combinado com seu termo quadrático para capturar retornos marginais decrescentes (Cox e Munger, 1989; Hogan, 1999), log do gasto do incumbente e do desafiante (Ansolabehere et al., 1994), log do gasto total per capita (Jackson, 1996), gasto total no distrito combinado com seu termo quadrático (Caldeira, Patterson e Markko, 1985), gasto total no distrito e a diferença entre o gasto do primeiro e do segundo colocados (Dawson e Zinser, 1976).

No presente artigo, ainda destaco uma variável de conjuntura política que pode influenciar o comparecimento: o número de alternativas disponíveis para os eleitores. Em relação à oferta de alternativas (número de candidatos ou partidos disponíveis), muitas vezes operacionalizada através do número efetivo de partidos (NEP), as hipóteses são de duas ordens. Uma delas é a de que, quanto maior a oferta de alternativas, maior seria a chance de o eleitor se sentir representado e isso também contribuiria para aumentar a

\footnotetext{
${ }^{9}$ Cabe a ressalva aqui levantada por meio do experimento de Ansolabehere et al. (1994) de que o tom negativo das campanhas poderia influenciar negativamente o comparecimento eleitoral. Embora os autores tenham encontrado resultados que apontem nesse sentido, esse não é um ponto pacífico na literatura. Mesmo as campanhas negativas podem influenciar positivamente o comparecimento porque elas geram informação que contribui para diferenciar os candidatos e deixam os eleitores mais atentos sobre as eleições e seus resultados (Finkel e Geer, apud Geys, 2006, p. 648). De todo modo, apurar o tom das campanhas eleitorais está além do escopo do presente artigo, mas é uma hipótese que ainda merece ser explorada.

10 Holbrook e McClurg (2005) não utilizaram diretamente a medida "gastos de campanha no distrito", mas o "total de contribuições do partido nacional para a campanha no distrito".
} 
probabilidade de comparecimento. A outra, oposta, é de que há um maior custo para a decisão do eleitor quando há maior oferta de alternativas, o que contribuiria para diminuir a probabilidade de comparecimento (Jackman, apud Blais, 2010). Entretanto, os achados para estudos com essas variáveis ainda são inconclusivos (Geys, 2006; Blais, 2010).

É preciso ainda controlar para eleições na qual um dos candidatos disputa a reeleição. Por um lado, a presença de um candidato à reeleição pode significar vantagem deste último ante os adversários, aumentando a certeza sobre quem será o vencedor e, por conseguinte, fazer com que o eleitor se sinta menos eficaz em produzir efeitos sobre o resultado da eleição, diminuindo o incentivo do indivíduo para ir às urnas (Dawson e Zinser, 1976). Entre as vantagens dos candidatos à reeleição estão o acesso a recursos financeiros e humanos inerentes ao exercício do cargo, o contato contínuo com potenciais eleitores durante o mandato, a maior visibilidade e cobertura da mídia, entre outras. A própria inércia lhes é favorável, pois seu desempenho já é conhecido, contrariamente àquele de um candidato desafiante. Por outro lado, a presença de um candidato à reeleição também pode motivar eleitores a irem às urnas para punir seu mau desempenho, especialmente se esses últimos lhe atribuírem culpa pela piora das condições de vida (Caldeira, Patterson e Markko, 1985). Parte dos estudos não controlou a presença de eleições com reeleição (Settle e Abrams, 1976; Pattie e Johnston, 1998; Matsukaka e Palda, 1999; Francia e Herrnson, 2004; Holbrook e McClurg, 2005). No entanto, entre aqueles estudos que incluíram o controle, não há resultados conclusivos nesse sentido (Dawson e Zinser, 1976; Ansolabehere et al., 1994). Alguns deles só utilizaram eleições com a presença de incumbentes e desafiantes, deixando de fora as chamadas open races e eleições com candidato único (Cox e Munger, 1989; Jackson, 1996). Outros estudos excluíram eleições de apenas um candidato, mas não deixaram claro se também foram excluídas eleições onde não havia incumbentes (Hogan, 1999).

Apresentados os mecanismos causais esperados para a associação de variáveis de conjuntura política ao comparecimento eleitoral, na próxima seção, exponho minha estratégia de análise empírica para testar essas hipóteses para o caso brasileiro.

\section{Comparecimento eleitoral nas eleições para prefeito em 2012}

Para esse exercício exploratório acerca do impacto das variáveis de conjuntura política sobre o comparecimento eleitoral no Brasil, escolhi analisar as eleições majoritárias de 2012. As eleições municipais no Brasil são relevantes pois os municípios e, em especial, os prefeitos têm atribuições importantes no plano político-federativo ao administrarem recursos e políticas relacionadas a educação, saúde e transporte coletivo, por exemplo. Além disso, o município é o nível de governo mais próximo do eleitor, onde se pode observar os representantes, envolver-se nas atividades políticas e vivenciar os resultados das políticas mais de perto. 
Diversas questões têm norteado a análise da dinâmica das eleições municipais no Brasil. Parte da literatura tem se preocupado especialmente com a reeleição e suas possíveis consequências, como a falta de alternância de poder ou o continuísmo das elites locais em detrimento do accountability eleitoral (Barreto, 2009; Brambor e Ceneviva, 2012). Outros autores têm se dedicado a verificar a importância de determinados fatores para o desempenho eleitoral para cargos em nível local, como o peso do dinheiro nas campanhas, da avaliação de governo, da estrutura organizacional dos partidos, entre outros (Braga e Pimentel Jr., 2013; Codato, Cervi e Perissinoto, 2013; Speck e Cervi, 2016; Borba e Cervi, 2017). Já uma parte da literatura tem se debruçado sobre os padrões de competição política, evidenciando estabilidade na competição pelas prefeituras (Limongi e Mesquita, 2008; Peixoto e Goulart, 2014; Silotto, 2017). É preciso ressaltar, contudo, que este artigo não é um estudo específico sobre dinâmica eleitoral municipal, mas recorre às eleições municipais como objeto empírico privilegiado para tratar da questão acerca da influência dos fatores de conjuntura política sobre os níveis de comparecimento e votos válidos.

A escolha pelas eleições de 2012 se deveu à maior proximidade temporal do Censo de 2010, cujas variáveis foram utilizadas como controle para o contexto socioeconômico (educação, renda, urbanização, composição etária, densidade demográfica) apontado por diversos estudos como relevante para as taxas de comparecimento. Além disso, nas eleições municipais mais recentes de 2016 , parte das variáveis de conjuntura política de interesse para este artigo esteve sob restrição quando foram implementados limites para gastos de campanha.

A unidade de análise deste artigo são as eleições municipais para prefeito em 2012. Foram analisadas 4.455 eleições, das quais 4.420 no primeiro turno e 35, no segundo turno ${ }^{11}$. Do total de eleições analisadas, em 43,70\% delas, prefeitos concorriam à reeleição e, em 2,36\% delas, havia apenas um único candidato disputando a vaga de prefeito.

Utilizo modelos multivariados de regressão linear simples para explicar os níveis de comparecimento eleitoral e votos válidos agregados ao nível municipal. Portanto, para não incorrer em falácia ecológica, associamos contextos com determinada característica (ex.: mais ou menos competição, mais ou menos gastos de campanha, maior ou menor fragmentação etc.) a maiores ou menores patamares de comparecimento e votos válidos. Os dados para este artigo foram obtidos a partir do repositório de dados eleitorais do Tribunal Superior Eleitoral (TSE), do portal Sidra do Instituto Brasileiro de Geografia e

\footnotetext{
11 Ficaram de fora da análise 1.113 municípios. Dentre eles, 1.075 apresentaram candidaturas com problemas judiciais que resultaram em cassações, indeferimentos, entre outros problemas; 77 tiveram a prestação de contas do financiamento de campanhas de apenas um candidato, embora houvesse mais candidatos na disputa, 4 não tiveram a prestação de contas de qualquer candidato nas eleições majoritárias e 2 não tiveram a prestação de contas de qualquer candidato nas eleições proporcionais; 5 eram municípios emancipados posteriormente ao Censo de 2010, sobre os quais não havia dados socioeconômicos disponíveis; além de Brasília e Fernando de Noronha que não contam com eleições municipais.
} 
EFEITOS DE COMPETIÇÃO, GASTOS DE CAMPANHA E FRAGMENTAÇÃO ELEITORAL

Estatística (IBGE, 2010) e do Atlas de Desenvolvimento Humano do Programa das Nações Unidas para o Desenvolvimento (PNUD, 2013).

As variáveis dependentes são o comparecimento medido em termos de comparecimento às urnas e em termos de votos válidos para as candidaturas de prefeito. Por essa razão, a primeira delas inclui casos em que os eleitores compareceram, mas podem ter votado em branco, nulo ou nominalmente em algum candidato. A segunda variável dependente, a do comparecimento em termos de votos válidos, descarta casos em que os eleitores não compareceram ou compareceram mas votaram branco ou nulo, fenômeno conhecido na literatura como alienação eleitoral. Essas variáveis foram operacionalizadas como a porcentagem dos eleitores que compareceram sobre o eleitorado apto e a porcentagem de votos válidos sobre esse mesmo eleitorado.

Procedi assim tendo em conta o debate acerca da provável defasagem do cadastro eleitoral em relação ao Censo, esse último realizado mais frequentemente. Apesar de o último recadastramento eleitoral antes de 2012 ter sido realizado no Brasil nos anos 1980, o fato de o Código Eleitoral de 1965 prever o cancelamento do título em caso de abstenção não justificada por três eleições consecutivas controla, em parte, essa defasagem. Embora o eleitorado apto em 2012 seja superior à população em idade de votar (16 anos ou mais) do Censo em 2010 em 79\% dos casos, testes mostram que há correlação significativa da ordem de 0,99 entre essas duas variáveis ${ }^{12}$. Além disso, os sinais das variáveis explicativas dos modelos nos quais as dependentes foram calculadas em relação à população em idade de votar não são diferentes se comparados aos resultados apresentados neste artigo, em relação ao eleitorado apto.

Nas eleições de 2012, a média da porcentagem de comparecimento sobre o eleitorado apto foi de 86,4, com desvio-padrão de 5,5, mínimo de 62,5 e máximo de 98,8. A média da porcentagem de votos válidos sobre o eleitorado apto foi de 81,1 , com desviopadrão de 7, mínimo de 36,8 e máximo de 97,5 (Tabela 1). Dessa maneira, observamos médias altas de comparecimento e de votos válidos nas eleições municipais de 2012, assim como uma variação importante do comparecimento e dos votos válidos. Essa variação observada contradiz a ideia de Campello de Souza de que a relação de votantes sobre o eleitorado inscrito tem utilidade quase nula como indicador positivo de participação por conta da vigência da obrigatoriedade do voto $\left(1976\right.$, p. 163) ${ }^{13}$.

\footnotetext{
12 Essa inflação de eleitores aptos ocorre provavelmente por conta de eleitores já falecidos ou que se mudaram de seu antigo domicílio eleitoral, porém não transferiram seus títulos para um novo domicílio eleitoral.

13 De acordo com o Código Eleitoral (Código Eleitoral, arts. 7, 11, § 10, e 367, § 20), as punições para quem não comparece são mínimas. O eleitor pode justificar sua ausência perante a Justiça Eleitoral no dia da eleição, em qualquer local de votação fora de seu domicílio eleitoral, ou em até 30 dias após as eleições, com documentos comprobatórios para a ausência. Após esse período, o eleitor pode obter a quitação eleitoral pagando uma multa no valor de $3 \%$ a $10 \%$ do salário mínimo vigente, o que equivalia de 18,66 a 62,20 reais em 2012 (valores de 2012). Em caso de não comparecimento sem justificativa por três eleições consecutivas, o título de eleitor é cancelado. Esse cancelamento impõe custos especialmente para pessoas que queiram tirar ou renovar passaporte, matricular-se em estabelecimento de ensino, inscrever-se ou tomar posse em concurso público, receber vencimentos do serviço público ou pedir financiamento em bancos públicos, por exemplo.
} 
Tabela 1

Definições e estatísticas descritivas das variáveis

\begin{tabular}{|l|c|c|c|c|}
\hline Variável & Média & $\begin{array}{c}\text { Desvio- } \\
\text { padrão }\end{array}$ & Mínimo & Máximo \\
\hline $\begin{array}{l}\text { \% de comparecimento sobre eleitorado } \\
\text { apto }\end{array}$ & 86,4 & 5,5 & 62,5 & 98,8 \\
\hline $\begin{array}{l}\% \text { de votos válidos sobre eleitorado } \\
\text { apto }\end{array}$ & 81,1 & 7 & 36,8 & 97,5 \\
\hline $\begin{array}{l}\% \text { da margem de vitória sobre o total } \\
\text { de votos válidos na eleição majoritária }\end{array}$ & 15,6 & 18,0 & 0,0 & 100,0 \\
\hline $\begin{array}{l}\text { Gastos de campanha per capita } \\
\text { (R\$2012) na eleição majoritária }\end{array}$ & 19,9 & 17 & 0,25 & 163,9 \\
\hline $\begin{array}{l}\text { Gastos de campanha per capita } \\
\text { (R\$2012) na eleição proporcional }\end{array}$ & 15,4 & 13,4 & 0,14 & 171,8 \\
\hline $\begin{array}{l}\text { Número efetivo de partidos na eleição } \\
\text { majoritária }\end{array}$ & 2,2 & 0,5 & 1,0 & 5,4 \\
\hline $\begin{array}{l}\text { Número efetivo de partidos na eleição } \\
\text { proporcional }\end{array}$ & 7,0 & 2,9 & 1,3 & 20,02 \\
\hline Magnitude da eleição proporcional & 10,3 & 3,1 & 9 & 55 \\
\hline $\begin{array}{l}\% \text { de pessoas com 18 anos ou mais } \\
\text { analfabetas }\end{array}$ & 17,4 & 10,8 & 0,97 & 47,43 \\
\hline $\begin{array}{l}\% \text { de pessoas com 25 anos ou mais com } \\
\text { ensino superior completo }\end{array}$ & 5,5 & 3,3 & 0,3 & 33,7 \\
\hline $\begin{array}{l}\% \text { de pessoas com 16 ou 17 anos de } \\
\text { idade }\end{array}$ & 3,8 & 0,5 & 1,0 & 9,2 \\
\hline$\%$ de pessoas com 18 a 69 anos & 63,4 & 4,7 & 39,9 & 87,9 \\
\hline$\%$ de pessoas com 70 anos ou mais & 5,6 & 1,7 & 0,7 & 14,5 \\
\hline$\%$ de população urbana & 63,2 & 22,1 & 4,2 & 100,0 \\
\hline $\begin{array}{l}\text { Renda mensal domiciliar per capita } \\
\text { mediana (R\$ 2010) }\end{array}$ & 376,5 & 170,4 & 22,5 & 1.150 \\
\hline Gini (multiplicado por 100) & 49,4 & 6,6 & 28,0 & 80,0 \\
\hline Área do distrito (km²) & $1.510,4$ & $5.785,7$ & 3,6 & $159.533,4$ \\
\hline Densidade demográfica (hab./km ${ }^{2}$ ) & 106,5 & 535,1 & 0,1 & 13024,6 \\
\hline Fon Eaça propra com
\end{tabular}

Fonte: Elaboração própria com dados do TSE, IBGE e Atlas de Desenvolvimento Humano do PNUD.

Nota: 4.455 observações. Dados sociodemográficos referentes ao ano de 2010. Dados de competição eleitoral referentes ao ano de 2012.

As variáveis independentes podem ser separadas em dois tipos: aquelas relativas ao contexto da competição política, as variáveis de interesse e as sociodemográficas, usadas como controle neste artigo. As variáveis de competição política são margem de vitória, gastos de campanha e número efetivo de partidos, além de controles para eleições com candidato único, com incumbente e de segundo turno. Uma vez que as eleições para prefeito ocorrem simultaneamente às eleições para vereador, variáveis de competição política relativas às eleições para a Câmara de Vereadores também foram incluídas, como o número efetivo de partidos, a magnitude dos distritos e os gastos de campanha nas eleições proporcionais. As variáveis margem de vitória e gastos de campanha foram operacionalizadas seguindo o modelo de Hogan (1999), discutido na seção anterior do presente artigo. Esse autor operacionalizou a margem de vitória como a diferença percentual de votos entre os dois primeiros colocados na eleição e os gastos de campanha 
como os gastos totais por eleitor registrado e seu termo quadrático ${ }^{14}$. Essa especificação oferece uma medida intuitiva e comparável para a margem de vitória e permite observar efeitos diferentes para os gastos de campanha a depender dos níveis destes. A expectativa é de que margem de vitória tenha efeito negativo sobre comparecimento, e gastos de campanha tenham efeito positivo (com retornos marginais decrescentes). Entretanto, a expectativa quanto ao impacto da fragmentação na disputa vista através do número efetivo de partidos é ambígua uma vez que a literatura não aponta conclusões nesse sentido. Operacionalizei essa variável pelo número efetivo de partidos e seu quadrático para permitir efeitos diferenciados a depender dos níveis de fragmentação. Controles importantes para a especificidade das eleições analisadas são os indicadores para candidaturas únicas, eleições com incumbentes e eleições de segundo turno. $O$ efeito esperado dos dois primeiros é negativo pois seriam eleições sem competição no caso das primeiras e com baixa competição no caso das segundas. A taxa de reeleição dos prefeitos no Brasil em 2008 foi de $66 \%$ e, nos anos de 2000 e 2004, de $58 \%{ }^{15}$. O efeito esperado da magnitude nas eleições proporcionais é positivo, ou seja, quanto maior a magnitude, maior a competição esperada e, consequentemente, o comparecimento.

Nas disputas pelas prefeituras em 2012, observamos uma grande variação em todos os fatores relativos à competição política. A média de gastos per capita por distrito foi de 19,9 reais, com desvio-padrão de 17 reais. A média da margem de vitória sobre o total de votos válidos foi de 15,6\%, com desvio-padrão de 18\%. Em dois municípios, inclusive, Balsa Nova-PR e Bananal-SP, houve empate entre os candidatos e, por isso, a margem de vitória foi igual a zero. O número efetivo médio de partidos foi de 2,2, com desvio-padrão de 0,5, mínimo de 1 e máximo de 5,4 candidatos, nas eleições mais fragmentadas. Nas eleições proporcionais, a média de gastos per capita por distrito foi de 15,4 reais, com desvio-padrão de 13,4 reais. A magnitude média dos distritos foi de 10,3 vagas, com desvio-padrão de 3,1 vagas. O número efetivo médio de partidos nas eleições para a Câmara de Vereadores foi de 7 partidos, com desvio-padrão de 2,9 partidos.

As variáveis sociodemográficas controlam o impacto de características da população do distrito, como educação, idade, renda e desigualdade de renda (Gini), além de características do distrito, como população urbana, área, densidade demográfica ${ }^{16}$.

\footnotetext{
14 Hogan (1999) também incluiu em seu modelo a margem de vitória na eleição anterior, porém essa especificação não faz sentido no caso brasileiro por conta do multipartidarismo e pelo fato de os protagonistas variarem de uma eleição para outra. Seu modelo contava ainda com controles para características demográficas dos distritos e indicadores para as unidades da federação. Entre os controles demográficos, o autor incluiu a renda domiciliar anual média, a porcentagem da população com 25 anos ou mais que tinha ao menos dois anos de ensino superior, a da população com 55 anos ou mais, a de trabalhadores na agricultura ou na mineração, a de trabalhadores empregados no serviço público, a da população negra, a da população hispânica e a da população asiática.

${ }_{15}$ Taxa de reeleição de prefeitos é a menor da história. Disponível em: <http://politica.estadao.com.br/noticias/eleicoes,taxa-de-reeleicao-de-prefeitos-e-a-menor-dahistoria,10000080149>. Acesso em: 28 fev. 2018.

$16 \mathrm{Na}$ literatura, o efeito esperado de educação, idade e renda é positivo (Dawson e Zinser, 1976; Cox e Munger, 1989; Geys, 2006), enquanto o efeito de desigualdade, densidade demográfica e população urbana é negativo, embora os estudos falhem em mostrar essa associação para as variáveis densidade demográfica
} 
Incluí também a variável que mede a proporção de analfabetos em idade de voto obrigatório porque o comparecimento é facultativo para esse grupo. Por fim, variáveis dicotômicas para diferentes regiões foram incluídas nos modelos para controlar os efeitos de desigualdades regionais não capturados pelo conjunto das variáveis sociodemográficas supracitadas. Na Tabela 1, disponibilizo as definições, operacionalizações e estatísticas descritivas de todas as variáveis utilizadas no presente artigo.

Na próxima seção, apresento e discuto os resultados dos modelos multivariados para comparecimento eleitoral nas eleições municipais de 2012.

\section{Qual o impacto do contexto da competição política no comparecimento eleitoral das eleições municipais?}

O principal objetivo deste artigo foi avaliar a ocorrência e a intensidade do impacto das variáveis de competição política sobre o comparecimento eleitoral em nível dos municípios. Optei por apresentar aqui os resultados nos quais as variáveis dependentes são calculadas em relação ao eleitorado apto. A seguir, apresento os resultados dos testes em duas subseções. Em um primeiro momento, testei modelos em que a variável dependente era a porcentagem de comparecimento às urnas sobre o eleitorado apto. Em um segundo momento, substituí a variável dependente pela porcentagem de votos válidos sobre o eleitorado apto.

\section{Comparecimento às urnas}

Inicialmente, testei três modelos para explicar a variável dependente porcentagem de comparecimento às urnas sobre o eleitorado apto. No primeiro deles, incluo apenas as variáveis de competição política; no segundo, apenas variáveis demográficas; e, no terceiro, todas as variáveis, de competição política e demográficas.

$\mathrm{Na}$ Tabela 2, é interessante notar que o modelo reduzido às variáveis de competição política explica $29,4 \%$ da variação do comparecimento às urnas. A título de comparação, o poder de explicação dos controles demográficos visto isoladamente é de $31,8 \%$ para o modelo de comparecimento às urnas. Por isso, embora as variáveis políticas expliquem menos a variação dos dados que as variáveis demográficas nos modelos parciais, o poder explicativo das primeiras não é desprezível perto do das segundas. Isso é ainda mais significativo porque as variáveis demográficas medem fatores de longo prazo enquanto as variáveis políticas medem fatores de curto prazo. Os modelos combinando

\footnotetext{
e população urbana (Geys, 2006). A ideia que perpassa essa expectativa é de que os vínculos interpessoais e a pressão social seriam reduzidos com a urbanização, também por conta de um maior individualismo em áreas densamente ocupadas. Tendo em mente o custo de deslocamento, incluo a variável tamanho da área do distrito para controlar para o impacto negativo que essa variável possa ter sobre o comparecimento (Lima Júnior, 1993).
} 
variáveis políticas e variáveis demográficas explicam $41,1 \%$ da variação do comparecimento.

Tabela 2
Regressões lineares simples para explicar a porcentagem de comparecimento às urnas sobre o eleitorado apto nas eleições para prefeito em 2012

\begin{tabular}{|c|c|c|c|}
\hline Variáveis & $\begin{array}{c}\text { (1) } \\
\text { Modelo de } \\
\text { variáveis de } \\
\text { competição } \\
\text { política }\end{array}$ & $\begin{array}{c}\text { (2) } \\
\text { Modelo de } \\
\text { variáveis } \\
\text { demográficas }\end{array}$ & $\begin{array}{c}\text { (3) } \\
\text { Modelo } \\
\text { completo }\end{array}$ \\
\hline $\begin{array}{l}\text { \% da margem de vitória sobre o total de votos } \\
\text { válidos na eleição majoritária }\end{array}$ & $\begin{array}{c}-0,0431 * * * \\
(0,00646) \\
\end{array}$ & & $\begin{array}{c}-0,0401 * * * \\
(0,00600) \\
\end{array}$ \\
\hline $\begin{array}{l}\text { Gastos de campanha per capita } \\
\text { (R\$2012) na eleição majoritária }\end{array}$ & $\begin{array}{c}0,0827 * * * \\
(0,0104)\end{array}$ & & $\begin{array}{l}0,106 * * * \\
(0,00960) \\
\end{array}$ \\
\hline $\begin{array}{l}\text { Quadrado dos gastos de campanha per capita } \\
\text { na eleição majoritária }\end{array}$ & $\begin{array}{l}-0,000399 * * * \\
(0,000101)\end{array}$ & & $\begin{array}{l}-0,000553 * * * \\
(9,52 \mathrm{e}-05)\end{array}$ \\
\hline $\begin{array}{l}\text { Número efetivo de partidos na eleição } \\
\text { majoritária }\end{array}$ & $\begin{array}{c}-4,777 * * * \\
(1,045)\end{array}$ & & $\begin{array}{c}-5,424 * * * \\
(1,020)\end{array}$ \\
\hline $\begin{array}{l}\text { Quadrado do número efetivo de partidos na } \\
\text { eleição majoritária }\end{array}$ & $\begin{array}{c}0,659 * * * \\
(0,188)\end{array}$ & & $\begin{array}{c}0,795 * * * \\
(0,184)\end{array}$ \\
\hline Eleição com candidato a prefeito único & $\begin{array}{l}-0,0801 \\
(0,715)\end{array}$ & & $\begin{array}{l}-0,433 \\
(0,650)\end{array}$ \\
\hline Eleição com candidato a prefeito à reeleição & $\begin{array}{c}0,178 \\
(0,140)\end{array}$ & & $\begin{array}{l}0,0992 \\
(0,128)\end{array}$ \\
\hline Eleição com segundo turno & $\begin{array}{l}-0,235 \\
(0,685)\end{array}$ & & $\begin{array}{l}-0,484 \\
(0,642)\end{array}$ \\
\hline $\begin{array}{l}\text { Gasto de campanha per capita ( } \$ \text { \$ 2012) } \\
\text { proporcional }\end{array}$ & $\begin{array}{c}0,0663 * * * \\
(0,0114)\end{array}$ & & $\begin{array}{c}0,0497 * * * \\
(0,0114)\end{array}$ \\
\hline $\begin{array}{l}\text { Quadrado dos gastos de campanha per capita } \\
\text { na eleição proporcional }\end{array}$ & $\begin{array}{l}-0,000429 * * * \\
(0,000123)\end{array}$ & & $\begin{array}{c}-0,000374 * * * \\
(0,000133)\end{array}$ \\
\hline $\begin{array}{l}\text { Número efetivo de partidos na eleição } \\
\text { proporcional }\end{array}$ & $\begin{array}{c}-1,395 * * * \\
(0,105)\end{array}$ & & $\begin{array}{c}-0,873 * * * \\
(0,101)\end{array}$ \\
\hline $\begin{array}{l}\text { Quadrado do número efetivo de partidos na } \\
\text { eleição proporcional }\end{array}$ & $\begin{array}{l}0,0664 * * * \\
(0,00642)\end{array}$ & & $\begin{array}{l}0,0414 * * * \\
(0,00613)\end{array}$ \\
\hline Magnitude da eleição proporcional & $\begin{array}{l}-0,262 * * * \\
(0,0343)\end{array}$ & & $\begin{array}{c}-0,255 * * * \\
(0,0372)\end{array}$ \\
\hline \% de pessoas com 18 anos ou mais analfabetas & & $\begin{array}{c}-0,0822 * * * \\
(0,0170) \\
\end{array}$ & $\begin{array}{c}-0,133 * * * \\
(0,0163)\end{array}$ \\
\hline $\begin{array}{l}\text { \% de pessoas com } 25 \text { anos ou mais com } \\
\text { ensino superior completo }\end{array}$ & & $\begin{array}{c}-0,319 * * * \\
(0,0333)\end{array}$ & $\begin{array}{c}-0,220 * * * \\
(0,0321)\end{array}$ \\
\hline$\%$ de pessoas com 16 ou 17 anos & & $\begin{array}{c}-1,081 * * * \\
(0,229)\end{array}$ & $\begin{array}{c}-0,982 * * * \\
(0,211)\end{array}$ \\
\hline$\%$ de pessoas com 18 a 69 anos & & $\begin{array}{l}0,282 * * * \\
(0,0386)\end{array}$ & $\begin{array}{l}0,243 * * * \\
(0,0363)\end{array}$ \\
\hline$\%$ de pessoas com 70 anos ou mais & & $\begin{array}{l}0,0898^{*} \\
(0,0516)\end{array}$ & $\begin{array}{l}-0,0347 \\
(0,0490)\end{array}$ \\
\hline \% de população urbana & & $\begin{array}{c}-0,0445 * * * \\
(0,00439)\end{array}$ & $\begin{array}{c}-0,0316 * * * \\
(0,00425)\end{array}$ \\
\hline
\end{tabular}




\begin{tabular}{|c|c|c|c|}
\hline Variáveis & $\begin{array}{c}\text { (1) } \\
\text { Modelo de } \\
\text { variáveis de } \\
\text { competição } \\
\text { política }\end{array}$ & $\begin{array}{c}(2) \\
\text { Modelo de } \\
\text { variáveis } \\
\text { demográficas }\end{array}$ & $\begin{array}{c}\text { (3) } \\
\text { Modelo } \\
\text { completo }\end{array}$ \\
\hline $\begin{array}{l}\text { Renda mensal domiciliar per capita mediana } \\
(\mathrm{R} \$ 2010)\end{array}$ & & $\begin{array}{l}-0,000770 \\
(0,00110) \\
\end{array}$ & $\begin{array}{l}-0,000479 \\
(0,00103)\end{array}$ \\
\hline Gini (multiplicado por 100) & & $\begin{array}{l}-0,157 * * * \\
(0,0156)\end{array}$ & $\begin{array}{c}-0,118^{* * *} \\
(0,0143)\end{array}$ \\
\hline Área do distrito $\left(\mathrm{km}^{2}\right)$ & & $\begin{array}{c}-0,000107 * * * \\
(2,17 \mathrm{e}-05) \\
\end{array}$ & $\begin{array}{c}-8,36 \mathrm{e}-05^{* * *} \\
(1,83 \mathrm{e}-05) \\
\end{array}$ \\
\hline Densidade demográfica (hab./km²) & & $\begin{array}{c}-0,000321^{* * *} \\
(8,47 \mathrm{e}-05) \\
\end{array}$ & $\begin{array}{c}0,000402 * * * \\
(0,000139) \\
\end{array}$ \\
\hline Norte & $\begin{array}{c}-2,363 * * * \\
(0,274) \\
\end{array}$ & $\begin{array}{c}3,214 * * * \\
(0,390)\end{array}$ & $\begin{array}{c}2,095 * * * \\
(0,362) \\
\end{array}$ \\
\hline Nordeste & $\begin{array}{c}-1,347 * * * \\
(0,194) \\
\end{array}$ & $\begin{array}{c}1,770 * * * \\
(0,311) \\
\end{array}$ & $\begin{array}{c}2,373 * * * \\
(0,307) \\
\end{array}$ \\
\hline Centro-Oeste & $\begin{array}{c}-1,823 * * * \\
(0,291) \\
\end{array}$ & $\begin{array}{c}1,472 * * * \\
(0,256) \\
\end{array}$ & $\begin{array}{c}-0,761 * * * \\
(0,271) \\
\end{array}$ \\
\hline Sul & $\begin{array}{c}2,652 * * * \\
(0,192) \\
\end{array}$ & $\begin{array}{c}2,836 * * * \\
(0,198)\end{array}$ & $\begin{array}{c}2,061^{* * *} \\
(0,192) \\
\end{array}$ \\
\hline Constante & $\begin{array}{l}100,7 * * *(1,454) \\
100,7 * * *(1,454)\end{array}$ & $\begin{array}{c}84,75^{* * *} \\
(3,188)\end{array}$ & $\begin{array}{c}97,65^{* * *} \\
(3,327)\end{array}$ \\
\hline $\mathrm{N}$ & 4.455 & 4.455 & 4.455 \\
\hline R-quadrado & 0,294 & 0,318 & 0,411 \\
\hline
\end{tabular}

Fonte: Elaboração própria com dados do TSE, IBGE e Atlas do Desenvolvimento Humano do PNUD.

Nota: Erros-padrão robustos em parênteses. Significância: $* * * p<0,01, * * p<0,05, * p<0,1$.

Notamos também que, na Tabela 2, a inclusão dos controles demográficos no modelo completo não prejudica a sobrevivência das variáveis de competição política. Os controles para eleições majoritárias de candidatura única, com candidato à reeleição e de segundo turno não alcançam níveis convencionais de significância estatística em nenhum dos modelos.

Em relação às expectativas acerca do efeito das variáveis independentes sobre as dependentes, observamos que os resultados confirmam as hipóteses acerca das variáveis políticas para o comparecimento ${ }^{17}$. Quanto maiores os gastos de campanha per capita, maior a porcentagem de comparecimento nas eleições municipais, apesar de confirmados os retornos marginais decrescentes desses últimos. Os resultados para a porcentagem da margem de vitória sobre os votos válidos seguem o sentido esperado de impacto negativo, ou seja, de que, quanto maior a margem de vitória, menor a porcentagem do

\footnotetext{
17 O foco principal deste artigo é analisar o impacto das variáveis de conjuntura política, por isso não vou me ater aos efeitos específicos das variáveis sociodemográficas e dos controles regionais. Entretanto, cabe ressaltar que os achados estão em conformidade com as hipóteses da literatura, com exceção do efeito negativo da proporção de pessoas com ensino superior sobre o comparecimento, mesmo após controladas as faixas etárias, a renda média e a proporção de analfabetos em cada município. Os estimadores das variáveis regionais também questionam a noção corrente de que o engajamento seria maior em áreas mais desenvolvidas, pois o comparecimento é maior no Norte, no Nordeste e no Sul se comparado ao do Sudeste. Contudo, esses são resultados que merecem ser analisados em pesquisas futuras.
} 
comparecimento. Esses são achados interessantes que apontam maior comparecimento às urnas em contextos com maior competição na disputa e com maior nível de esforço das elites por meio dos gastos de campanha. Isso acontece mesmo depois de controlados os efeitos das variáveis de competição política das eleições proporcionais, das variáveis demográficas e de outros fatores contextuais da disputa para prefeitura, como eleições com candidatos únicos e com candidatos à reeleição e eleições de segundo turno.

Ainda na Tabela 2, observamos o resultado de que, quanto maior a fragmentação medida pelo número efetivo de partidos (NEP), menor é a porcentagem de comparecimento, já controladas as disputas com candidatos únicos e com incumbentes. Entretanto, os estimadores evidenciam que, no caso de aumento do número efetivo de partidos, os retornos marginais para o comparecimento são crescentes. Conforme o esperado, eleições com candidatos únicos, ou seja, sem competição política, estão associadas a um menor comparecimento, porém esse resultado não é estatisticamente significativo no modelo parcial e tampouco no completo. Os estimadores para a presença de incumbentes são positivos e, para as eleições de segundo turno, são negativos, ainda que inconclusivos, pois nenhum deles é estatisticamente significativo.

Entretanto, no modelo completo, o efeito da porcentagem da margem de vitória cai em $7 \%$ e o efeito dos gastos de campanha per capita aumentam em $28 \%$ no modelo completo. $\mathrm{O}$ efeito do número efetivo de partidos também aumenta no modelo completo em $11 \%$.

Passemos agora a avaliar a magnitude do efeito médio das variáveis de interesse principais deste artigo, quais sejam, a margem de vitória, os gastos de campanha e o número efetivo de partidos. No modelo completo, o efeito médio previsto do aumento em um ponto percentual na margem de vitória é de diminuição de 0,04 ponto percentual no comparecimento. Numa disputa com 10 pontos percentuais de diferença entre o primeiro e o segundo colocado, por exemplo, em que o primeiro tem $55 \%$ e o segundo $45 \%$ dos votos, o comparecimento previsto é 0,4 ponto percentual menor do que se houvesse um empate entre eles. Se a diferença fosse maior, em que o primeiro tivesse $55 \%$ e o segundo, $35 \%$, o comparecimento previsto nesse caso seria 0,8 ponto percentual menor comparado a um empate. No caso de 40 pontos percentuais de diferença entre os candidatos, 0 comparecimento previsto seria 1,6 ponto percentual menor.

Já a magnitude dos efeitos previstos do aumento dos gastos de campanha e do número efetivo de partidos varia a depender dos valores que esses últimos assumirem. 0 primeiro real per capita gasto na campanha retorna aproximadamente 0,1 ponto percentual em comparecimento. Aumentando o gasto médio per capita, equivalente a cerca de 20 reais, para 21 reais, a previsão do crescimento no comparecimento é de 0,08 ponto percentual, enquanto aumentando de 50 para 51 reais, é de mais 0,05 ponto percentual. Portanto, o retorno marginal do gasto de campanha per capita é decrescente, como pode ser observado no Gráfico 1 (Comparecimento a): 


\section{Gráfico 1}

Efeitos marginais do gasto per capita e do número efetivo de partidos sobre o comparecimento (\%)

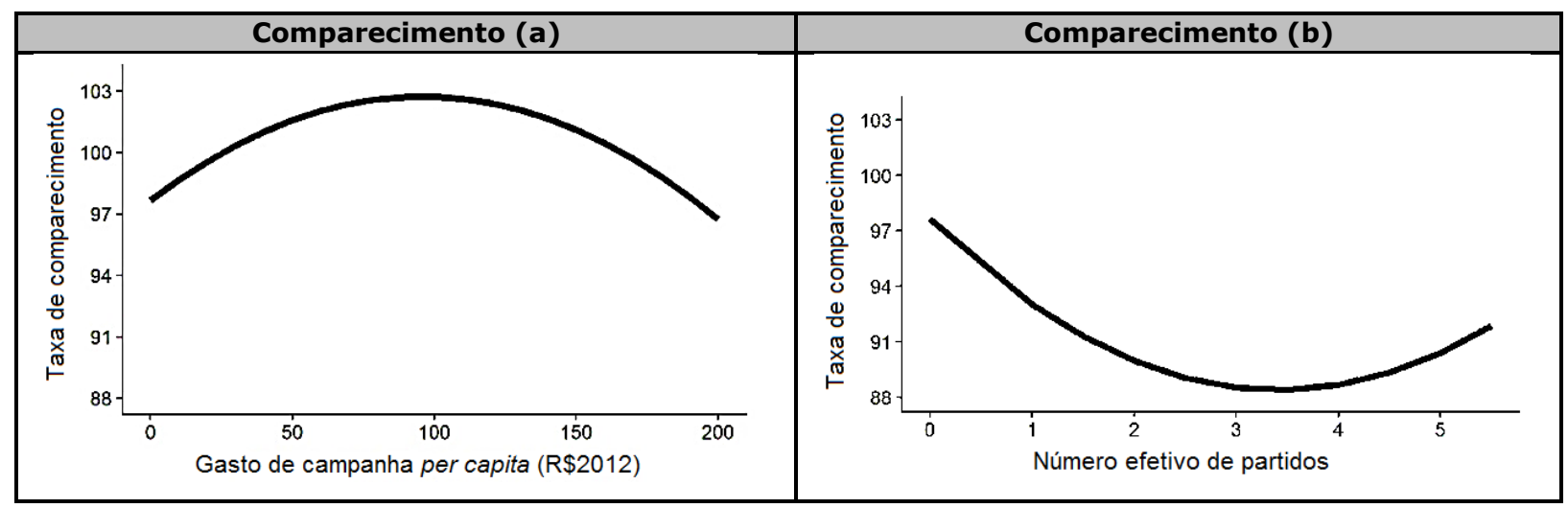

Fonte: Elaboração própria com dados do TSE, IBGE e Atlas de Desenvolvimento Humano do PNUD.

Nota: Os valores estimados de taxa de comparecimento ultrapassam o valor de 100 porque o comparecimento foi modelado, por aproximação, como uma variável contínua no modelo de regressão linear e não como uma variável limitada. Entretanto, o objetivo do gráfico é apenas apresentar o efeito não linear dos gastos de campanha e do número efetivo de partidos das eleições majoritárias sobre os níveis de comparecimento.

De forma semelhante, a fragmentação mínima de um partido efetivo implica a diminuição de 5,4 pontos percentuais no comparecimento. A mudança de um para dois partidos efetivos na disputa gera uma queda menor, de 3,8 pontos percentuais, ao passo que a mudança de quatro para cinco partidos efetivos está associada a um aumento de 0,9 ponto percentual no comparecimento. Acima de um ponto crítico, que é um NEP de 3,4, o efeito da fragmentação passa a ser positivo sobre o comparecimento, como pode ser visto no Gráfico 1 (Comparecimento b). Esse achado sinaliza que, nos níveis menores, a fragmentação pode estar relacionada à falta de competição e isso inibe o comparecimento, mas, nos níveis maiores, pode estar associada a uma incerteza maior sobre o resultado da eleição, fator esse que tende a aumentar o comparecimento. Notamos ainda que o peso dos efeitos das variáveis de competição política das eleições majoritárias é relativamente maior que o das eleições proporcionais sobre o comparecimento.

A fim de verificar a robustez desses achados, testei outras especificações de modelos e de variáveis (para os gastos de campanha e para a margem de vitória) inspirados na literatura. Apresento os resultados para esses testes na Tabela 1 do Apêndice. Nessa tabela, verificamos que, a despeito das diferentes especificações, os resultados se mantêm no sentido esperado. Gastos de campanha continuam a ter um efeito positivo com retornos marginais decrescentes, a porcentagem da margem de vitória sobre os votos válidos tem um impacto negativo e a fragmentação tem um efeito negativo com retornos marginais crescentes.

A seguir, discuto os resultados obtidos para esses mesmos testes quando a variável dependente é a porcentagem de votos válidos. 
EFEITOS DE COMPETIÇÃO, GASTOS DE CAMPANHA E FRAGMENTAÇÃO ELEITORAL

\section{Votos válidos}

Ao repetir esses mesmos testes para a variável dependente porcentagem de votos válidos sobre o eleitorado apto na Tabela 3, observamos resultados semelhantes aos referidos para a porcentagem de comparecimento na Tabela 2. Na Tabela 3, o modelo reduzido às variáveis de competição política tem um desempenho melhor que os apresentados na subseção "Comparecimento às urnas" e explica nada menos que 45,1\% da variação dos dados, enquanto o modelo parcial das variáveis demográficas explica $25,4 \%$. Esse achado chama a atenção por conta do peso maior das variáveis de conjuntura em comparação com as variáveis sociodemográficas, mais permanentes, para explicar a porcentagem de votos válidos ${ }^{18}$. O modelo combinando variáveis políticas e variáveis demográficas também explica uma variação maior da porcentagem de votos válidos, de $52,4 \%$, se comparado ao comparecimento em si.

Tabela 3

\section{Regressões lineares simples para explicar a porcentagem de votos válidos sobre o eleitorado apto nas eleições para prefeito em 2012}

\begin{tabular}{|c|c|c|c|}
\hline Variáveis & $\begin{array}{c}\text { (1) } \\
\text { Modelo de } \\
\text { variáveis de } \\
\text { competição } \\
\text { política }\end{array}$ & $\begin{array}{c}(2) \\
\text { Modelo de } \\
\text { variáveis } \\
\text { demográficas }\end{array}$ & $\begin{array}{c}(3) \\
\text { Modelo } \\
\text { completo }\end{array}$ \\
\hline $\begin{array}{l}\text { \% da margem de vitória sobre o total } \\
\text { de votos válidos na eleição majoritária }\end{array}$ & $\begin{array}{c}-0,0897 * * * \\
(0,00916)\end{array}$ & & $\begin{array}{c}-0,0853 * * * \\
(0,00897)\end{array}$ \\
\hline $\begin{array}{l}\text { Gastos de campanha per capita ( } \mathrm{R} \$ 2012) \text { na } \\
\text { eleição majoritária }\end{array}$ & $\begin{array}{c}0,0987 * * * \\
(0,0116)\end{array}$ & & $\begin{array}{l}0,122 * * * \\
(0,0109)\end{array}$ \\
\hline $\begin{array}{l}\text { Quadrado dos gastos de campanha per capita } \\
\text { na eleição majoritária }\end{array}$ & $\begin{array}{c}-0,000519 * * * \\
(0,000106)\end{array}$ & & $\begin{array}{c}-0,000666 * * x \\
(0,000101)\end{array}$ \\
\hline $\begin{array}{l}\text { Número efetivo de partidos na eleição } \\
\text { majoritária }\end{array}$ & $\begin{array}{l}-2,750 * \\
(1,424)\end{array}$ & & $\begin{array}{c}-3,388 * * \\
(1,450)\end{array}$ \\
\hline $\begin{array}{l}\text { Quadrado do número efetivo de partidos na } \\
\text { eleição majoritária }\end{array}$ & $\begin{array}{c}0,278 \\
(0,258)\end{array}$ & & $\begin{array}{c}0,415 \\
(0,264)\end{array}$ \\
\hline Eleição com candidato a prefeito único & $\begin{array}{c}-13,13 * * * \\
(1,408)\end{array}$ & & $\begin{array}{c}-13,58 * * * \\
(1,432)\end{array}$ \\
\hline Eleição com candidato a prefeito à reeleição & $\begin{array}{l}0,00838 \\
(0,156)\end{array}$ & & $\begin{array}{r}-0,0430 \\
(0,146) \\
\end{array}$ \\
\hline Eleição com segundo turno & $\begin{array}{c}1,028 \\
(1,023)\end{array}$ & & $\begin{array}{l}1,526 * \\
(0,907)\end{array}$ \\
\hline $\begin{array}{l}\text { Gasto de campanha per capita ( } \mathrm{R} \$ 2012) \text { na } \\
\text { eleição proporcional }\end{array}$ & $\begin{array}{c}0,0668^{* * *} \\
(0,0131)\end{array}$ & & $\begin{array}{c}0,0532 * * * \\
(0,0129)\end{array}$ \\
\hline $\begin{array}{l}\text { Quadrado dos gastos de campanha per capita } \\
\text { na eleição proporcional }\end{array}$ & $\begin{array}{c}-0,000359 * * \\
(0,000141) \\
\end{array}$ & & $\begin{array}{c}-0,000331 * * \\
(0,000146)\end{array}$ \\
\hline
\end{tabular}

\footnotetext{
18 Alguém poderia objetar que esse crescimento do $\mathrm{R}^{2}$ se deve ao fato de os votos válidos estarem presentes tanto na variável dependente (em seu numerador) quanto na variável independente (denominador da porcentagem da margem de vitória). No entanto, a correlação entre ambas as variáveis é de $-0,38$, ou seja, elas não podem ser resumidas a um único fenômeno. Além disso, o alto $\mathrm{R}^{2}$ para o modelo das variáveis políticas se mantém mesmo se a porcentagem da margem de vitória sobre votos válidos for substituída apenas pela margem de vitória bruta e seu termo quadrático $\left(R^{2}=43,45\right)$.
} 


\begin{tabular}{|c|c|c|c|}
\hline Variáveis & $\begin{array}{c}\text { (1) } \\
\text { Modelo de } \\
\text { variáveis de } \\
\text { competição } \\
\text { política }\end{array}$ & $\begin{array}{c}\text { (2) } \\
\text { Modelo de } \\
\text { variáveis } \\
\text { demográficas }\end{array}$ & $\begin{array}{c}(3) \\
\text { Modelo } \\
\text { completo }\end{array}$ \\
\hline $\begin{array}{l}\text { Número efetivo de partidos na eleição } \\
\text { proporcional }\end{array}$ & $\begin{array}{c}-1,833 * * * \\
(0,124)\end{array}$ & & $\begin{array}{c}-1,311^{* * *} \\
(0,120)\end{array}$ \\
\hline $\begin{array}{l}\text { Quadrado do número efetivo de partidos na } \\
\text { eleição proporcional }\end{array}$ & $\begin{array}{l}0,0829 * * * \\
(0,00777)\end{array}$ & & $\begin{array}{l}0,0574 * * * \\
(0,00754)\end{array}$ \\
\hline Magnitude da eleição proporcional & $\begin{array}{c}-0,421 * * * \\
(0,0421)\end{array}$ & & $\begin{array}{c}-0,322 * * * \\
(0,0481)\end{array}$ \\
\hline $\begin{array}{l}\text { \% de pessoas com } 18 \text { anos ou mais } \\
\text { analfabetas }\end{array}$ & & $\begin{array}{c}-0,126 * * * \\
(0,0210)\end{array}$ & $\begin{array}{c}-0,167^{* * *} \\
(0,0180)\end{array}$ \\
\hline $\begin{array}{l}\text { \% de pessoas com } 25 \text { anos ou mais com } \\
\text { ensino superior completo }\end{array}$ & & $\begin{array}{c}-0,339 * * * \\
(0,0496)\end{array}$ & $\begin{array}{c}-0,221 * * * \\
(0,0394)\end{array}$ \\
\hline$\%$ de pessoas com 16 ou 17 anos & & $\begin{array}{c}-1,246 * * * \\
(0,300) \\
\end{array}$ & $\begin{array}{c}-0,990 * * * \\
(0,235)\end{array}$ \\
\hline$\%$ de pessoas com 18 a 69 anos & & $\begin{array}{c}0,223 * * * \\
(0,0544)\end{array}$ & $\begin{array}{c}0,209 * * * \\
(0,0410)\end{array}$ \\
\hline$\%$ de pessoas com 70 anos ou mais & & $\begin{array}{l}0,230 * * * \\
(0,0755)\end{array}$ & $\begin{array}{l}-0,00595 \\
(0,0603)\end{array}$ \\
\hline \% de população urbana & & $\begin{array}{c}-0,0458 * * * \\
(0,00578)\end{array}$ & $\begin{array}{c}-0,0331 * * * \\
(0,00481)\end{array}$ \\
\hline $\begin{array}{l}\text { Renda mensal domiciliar per capita mediana } \\
(\mathrm{R} \$ 2010)\end{array}$ & & $\begin{array}{l}-0,00296 \\
(0,00183)\end{array}$ & $\begin{array}{l}-0,00232 * \\
(0,00125)\end{array}$ \\
\hline Gini (multiplicado por 100 ) & & $\begin{array}{c}-0,175 * * * \\
(0,0206)\end{array}$ & $\begin{array}{c}-0,141^{* * *} \\
(0,0164)\end{array}$ \\
\hline Área do distrito $\left(\mathrm{km}^{2}\right)$ & & $\begin{array}{c}-9,69 e-05^{* * *} \\
(1,97 e-05)\end{array}$ & $\begin{array}{c}-6,99 \mathrm{e}-05^{* * *} \\
(1,69 \mathrm{e}-05)\end{array}$ \\
\hline Densidade demográfica (hab./km²) & & $\begin{array}{c}-0,00131 * * * \\
(0,000172)\end{array}$ & $\begin{array}{c}-0,000464 * * * \\
(0,000150)\end{array}$ \\
\hline Norte & $\begin{array}{c}-1,168 * * * \\
(0,316)\end{array}$ & $\begin{array}{c}4,447 * * * \\
(0,481)\end{array}$ & $\begin{array}{c}2,837 * * * \\
(0,418)\end{array}$ \\
\hline Nordeste & $\begin{array}{c}-1,461 * * * \\
(0,214)\end{array}$ & $\begin{array}{c}2,187 * * * \\
(0,383)\end{array}$ & $\begin{array}{c}2,269 * * * \\
(0,349)\end{array}$ \\
\hline Centro-Oeste & $\begin{array}{c}-1,055 * * * \\
(0,337)\end{array}$ & $\begin{array}{c}2,806 * * * \\
(0,367)\end{array}$ & $\begin{array}{r}-0,0755 \\
(0,320)\end{array}$ \\
\hline Sul & $\begin{array}{c}3,568 * * * \\
(0,228)\end{array}$ & $\begin{array}{c}4,077 * * * \\
(0,302)\end{array}$ & $\begin{array}{c}2,965^{* * *} * \\
(0,232)\end{array}$ \\
\hline Constante & $\begin{array}{c}97,22 * * * \\
(1,839)\end{array}$ & $\begin{array}{c}85,21 * * * \\
(4,099)\end{array}$ & $\begin{array}{c}97,75^{* * *} \\
(3,699)\end{array}$ \\
\hline $\mathrm{N}$ & 4.455 & 4.455 & 4.455 \\
\hline R-quadrado & 0,451 & 0,254 & 0,524 \\
\hline
\end{tabular}

Fonte: Elaboração própria com dados do TSE, IBGE e Atlas de Desenvolvimento Humano do PNUD.

Nota: Erros-padrão robustos em parênteses. Significância: $* * * p<0,01, * * p<0,05, * p<0,1$.

À semelhança do que ocorre na Tabela 2, na Tabela 3, notamos que todas as variáveis de competição política de interesse sobrevivem, mesmo após a inclusão dos controles demográficos no modelo completo. Nesse modelo, diferente do que ocorre na Tabela 2, os efeitos marginais crescentes do número efetivo de partidos na eleição majoritária não são confirmados, somente o são nas eleições proporcionais. O controle para eleições de candidatura única mostra impacto negativo e significativo e o controle 
para eleição de segundo turno mostra um efeito positivo e significativo. Já o controle para eleições com candidatos incumbentes continua a ser inconclusivo.

No que diz respeito à direção dos efeitos das variáveis independentes sobre as dependentes, na Tabela 3 observamos praticamente a mesma configuração da Tabela $2^{19}$. Dito de outra maneira, maior margem percentual de vitória e maior fragmentação na disputa diminuem a porcentagem de votos válidos enquanto maiores gastos de campanha a aumenta. Permanecem, apenas, os retornos marginais decrescentes para os gastos de campanha. O que vemos de diferente é que os estimadores para o efeito da candidatura única são consistentemente negativos em relação aos votos válidos, embora tenham permanecido inconclusivos em relação às eleições com candidato à reeleição. Na falta de competição, há menos votos válidos, o que condiz com a expectativa teórica inicial, entretanto o segundo turno parece interferir positivamente nos votos válidos.

A variação da força dos efeitos do modelo parcial para o modelo completo guarda algumas diferenças da Tabela 2 para a Tabela 3. O que vemos de diferente na comparação dos modelos parciais e completos para votos válidos em relação ao comparecimento é que o efeito da margem de vitória percentual cai menos, $5 \%$ contra $7 \%$, que o impacto dos gastos de campanha aumenta menos, $23,5 \%$ contra $28 \%$, e que o efeito da fragmentação sobe mais, $16,5 \%$ contra $11 \%$. Já o impacto da eleição com incumbente cresce, quando antes diminuía, enquanto as magnitudes do efeito da eleição com candidato único e de segundo turno aumentam, embora com menos força se comparadas aos modelos do comparecimento.

No modelo completo da Tabela 3, verificamos que o efeito médio do aumento de um ponto percentual na margem de vitória é de menos 0,08 ponto percentual nos votos válidos. Esse efeito é aproximadamente o dobro do que observamos para o comparecimento. Por essa razão, a previsão de queda nos votos válidos é de 0,85 ponto percentual caso uma disputa deixe de ter um empate para ter 10 pontos percentuais de margem de vitória. Se essa diferença entre os dois primeiros candidatos se amplia para 40 pontos percentuais (por exemplo, 70\%-30\%), os votos válidos previstos caem 3,4 pontos percentuais.

O primeiro real per capita gasto na campanha retorna aproximadamente 0,12 ponto percentual em votos válidos. Aumentando o gasto médio per capita, equivalente a cerca de 20 reais, para 21 reais, a previsão do crescimento nos votos válidos é de 0,095 ponto percentual. Dessa maneira, observamos novamente que o retorno marginal do gasto de campanha per capita é decrescente, como pode ser observado no Gráfico 2 (Votos

\footnotetext{
19 Conforme já referido na nota 15, o enfoque deste artigo privilegiou os efeitos das variáveis de conjuntura política. Entretanto, assim como ocorre com os modelos do comparecimento, observamos resultados que nos chamam a atenção em relação às variáveis sociodemográficas e regionais para o modelo dos votos válidos. O efeito negativo e mais forte da proporção de pessoas com ensino superior que a de analfabetos sobre os votos válidos se repete. As regiões Norte, Nordeste e Sul têm efeito positivo sobre votos válidos, assim como ocorre para o comparecimento, se comparadas à região Sudeste. Esses são achados que também merecem investigação futura.
} 
válidos a). A fragmentação mínima de um partido efetivo implica a diminuição de 3,4 pontos percentuais nos votos válidos. A mudança de um para dois partidos efetivos na disputa gera uma queda menor, de 2,6 pontos percentuais, ao passo que a mudança de quatro para cinco partidos efetivos está associada a uma diminuição de 0,07 ponto percentual nos votos válidos. Acima do ponto crítico, um NEP de 4,1, o efeito da fragmentação passa a ser positivo sobre o comparecimento, como pode ser visto no Gráfico 2 (Votos válidos b). As candidaturas únicas, por sua vez, implicariam uma diminuição ainda maior, de 13,6 pontos percentuais, na variável dependente, enquanto nas eleições de segundo turno há um aumento de 1,5 ponto percentual. Assim como acontece nos modelos de comparecimento, observamos que a força dos efeitos das variáveis de competição política das eleições majoritárias é relativamente maior que a das eleições proporcionais sobre os votos válidos. Interessante ressaltar que a fragmentação na eleição proporcional tem um efeito negativo com retorno marginal crescente sobre votos válidos na eleição para prefeito.

\section{Gráfico 2}

\section{Efeitos marginais do gasto per capita e do número efetivo de partidos sobre os votos válidos (\%)}

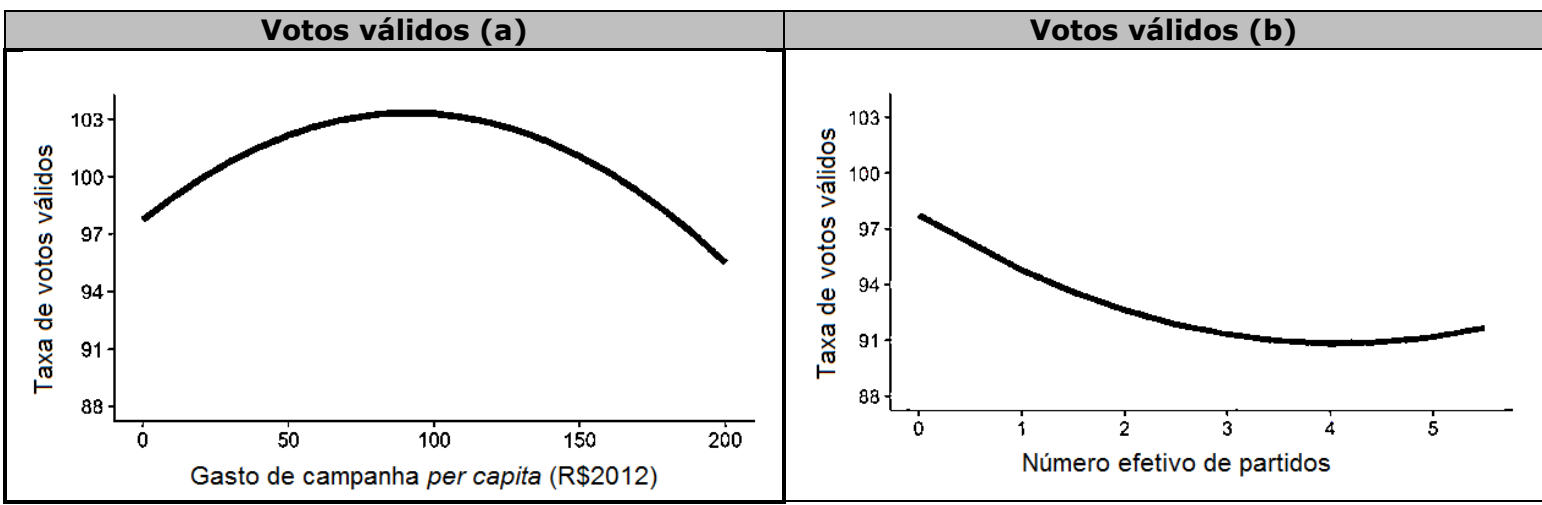

Fonte: Elaboração própria com dados do TSE, IBGE e Atlas do Desenvolvimento Humano do PNUD.

Nota: Os valores estimados de da taxa de votos válidos ultrapassam o valor de 100 porque os votos válidos foram modelados, por aproximação, como uma variável contínua no modelo de regressão linear e não como uma variável limitada. Entretanto, o objetivo do gráfico é apenas apresentar o efeito não linear dos gastos de campanha e do número efetivo de partidos das eleições majoritárias sobre os níveis de votos válidos.

Também testei outras especificações de modelos e de variáveis (para os gastos de campanha e para a margem de vitória) inspirados na literatura, à semelhança do que fiz para o comparecimento. Apresento os resultados para esses testes na Tabela 2 do Apêndice. Nessa tabela, verificamos que, a despeito das diferentes especificações, os resultados se mantêm no sentido esperado na maioria dos modelos. Gastos de campanha continuam a ter um efeito positivo com retornos marginais decrescentes, a porcentagem da margem de vitória sobre os votos válidos, um impacto negativo e a fragmentação, um efeito negativo. 
EFEITOS DE COMPETIÇÃO, GASTOS DE CAMPANHA E FRAGMENTAÇÃO ELEITORAL

Os estimadores obtidos neste artigo mostram que existe associação entre as variáveis de competição política, o comparecimento e os votos válidos nas eleições. Os dados confirmam as hipóteses correntes na literatura de que a margem de vitória se relaciona negativamente com a variável dependente e de que os gastos de campanha se relacionam positivamente, com retornos marginais decrescentes. Os dados apontam fortemente que a fragmentação tem um impacto negativo (com retornos marginais crescentes sobre o comparecimento, mas não sobre votos válidos), embora os resultados de outros estudos anteriores sejam inconclusivos. Além disso, os resultados mostram que os votos válidos são muito sensíveis à falta de competição capturada no indicador de candidaturas únicas. É intrigante que, no caso de candidaturas únicas, os estimadores não acusem um impacto negativo sistemático sobre o comparecimento, mas apenas sobre os votos válidos. É importante lembrar que esse tipo de eleição, sem competição, acontece principalmente, se não unicamente, em cidades pequenas. Em 2012, todas as candidaturas únicas ocorreram em municípios com menos de 30 mil eleitores aptos. Talvez nesses contextos a ausência de competição não seja suficiente para diminuir o comparecimento em si, apesar de gerar efeito sobre os votos válidos. De todo modo, é notável que esses achados referentes aos efeitos da conjuntura política de curto prazo alcancem a magnitude observada diante de regras que estabelecem o comparecimento obrigatório e se mantenham presentes mesmo se controlados os efeitos mais permanentes das variáveis sociodemográficas e das variáveis de competição política de eleições proporcionais.

\section{Considerações finais}

Os estudos sobre comparecimento eleitoral apontam que uma série de fatores condicionam esse fenômeno. De forma resumida, podemos dizer que são fatores de longo prazo, como o contexto sociodemográfico e as atitudes individuais, e fatores de curto prazo, como a conjuntura política. Dentre esses últimos, destacam-se três indicadores: o da competição política, medido pelo acirramento da disputa e mais comumente chamado de margem de vitória; o da mobilização das elites, medido pela intensidade ou pelo volume das campanhas (através dos gastos dos candidatos); e, finalmente, o da fragmentação política, medido pelo número de alternativas disponíveis a serem votadas, ou seja, pelo número efetivo de partidos.

Neste artigo, observei uma lacuna na literatura brasileira acerca da influência das variáveis de conjuntura política sobre o comparecimento eleitoral. Também mostrei que, embora o voto obrigatório desloque a atenção dos pesquisadores para o fenômeno das abstenções e da alienação eleitoral (votos brancos e nulos), há uma variação importante sobre a participação eleitoral (comparecimento e votos válidos) que merece ser analisada e explicada. Além disso, verifiquei que as variáveis de mobilização política influenciam o comparecimento e os votos válidos, mesmo se controlarmos o impacto de fatores de longo prazo como aqueles que caracterizam o contexto sociodemográfico. Mostrei ainda que, 
diante da simultaneidade das eleições majoritárias e proporcionais, as variáveis de conjuntura política das eleições para vereador também exercem influência sobre as eleições para prefeito. Mais especificamente, observamos que a margem de vitória percentual e a fragmentação na eleição majoritária têm um efeito negativo sobre o comparecimento e os votos válidos, enquanto os gastos de campanha têm um efeito positivo sobre eles. Vale lembrar que a fragmentação apresentou retornos marginais crescentes para os votos válidos e os gastos de campanha apresentaram retornos marginais decrescentes para comparecimento e votos válidos. Esse é um achado interessante porque, sendo o comparecimento obrigatório segundo a legislação, não era esperado que fatores conjunturais o afetassem de forma significativa. Fica assim relativizada a ideia de que, sendo o voto obrigatório no Brasil, não valeria a pena se dedicar à investigação do fenômeno positivo da participação eleitoral.

A robustez dos resultados obtidos neste artigo se verifica também tanto pela consistência dos achados com diferentes operacionalizações das variáveis de interesse, especialmente a margem de vitória e os gastos de campanha, quanto pelas diferentes especificações de modelos testados conforme o debate presente na literatura, apresentados no Apêndice. No Brasil, este artigo ainda tem um caráter exploratório diante da carência de outros estudos com esse escopo que utilizam dados de eleições brasileiras. Em exercícios futuros, é possível, ainda, analisar como as variáveis de conjuntura política afetam o comparecimento e os votos válidos em eleições para outros cargos no país.

\section{Referências bibliográficas}

AnsolAbehere, S., et al. "Does attack advertising demobilize the electorate?". The American Political Science Review, vol. 88, no 4, p. 829-838, 1994.

Barreto, A. A. B. "Reeleição para o Executivo municipal no Brasil (2000-2008)". Revista Debates, vol. 3, no 2, p. 97-115, 2009.

BLAIS, A. Political participation. In LedUC, L.; NIEMI, R. G.; NorRIS, P. (eds.). Comparing democracies 3: elections and voting in the $21^{\text {st }}$ : Century. London: Sage, p. 165-183, 2010.

BORBA, F.; CERVI, E. "Relação entre propaganda, dinheiro e avaliação de governo no desempenho de candidatos em eleições majoritárias no Brasil". Opinião Pública, vol. 23, no 3, p. 754-785, 2017.

BRAgA, M. S. S.; PImentel JR., J. "Estrutura e organização partidária municipal nas eleições de $2012 . "$ Cadernos Adenauer XIV, no 2, p. 13-36, 2013.

Brambor, T.; Ceneviva, R. "Reeleição e continuísmo nos municípios brasileiros". Novos Estudos, vol. 93, p. 9-21, 2012.

Caldeira, G.; PATterson, S.; MARKKo, G. "The mobilization of voters in congressional elections". The Journal of Politics, vol. 47, no 2, p. 490-509, 1985.

CAmpbell, A., et al. The American voter. Chicago: The University of Chicago Press, 1960.

CAmpello de SouzA, M. C. Estado e partidos políticos no Brasil. São Paulo: Editora Alfa-Omega, 1976. 
Codato, A.; Cervi, E.; Perissinoto, R. "Quem se elege prefeito no Brasil? Condicionantes do sucesso eleitoral em 2012". Cadernos Adenauer XIV, no 2, p. 61-84, 2013.

Cox, G.; Munger, M. "Closeness, expenditures, and turnout in the 1982 US House elections". The American Political Science Review, vol. 83, no 1, p. 217-231, 1989.

DAWSON, P.; ZINSER, J. "Political finance and participation in congressional elections". The Annals of the American Academy, no 425, p. 59-73, 1976.

Downs, A. Uma teoria econômica da democracia. São Paulo: Edusp, 2013.

Figueiredo, M. A decisão do voto: democracia e racionalidade. Belo Horizonte: Editora UFMG, 2008.

FISHER, J. Persuasion and mobilization efforts by parties and candidates. In: FISHER, J., et al. (eds.)., The routledge handbook of elections, voting behavior and public opinion. New York: Routledge, $\mathrm{p}$. 280-292, 2018.

FRANCIA, P.; HeRRnSON, P. "The synergistic effect of campaign effort and election reform on voter turnout in state legislative elections". State Politics and Policy Quarterly, vol. 4, no 1, p. 74-93, 2004.

Gallego, A. Unequal political participation worldwide. New York: Cambridge University Press, 2015.

GEYS, B. "Explaining voter turnout: a review of aggregate-level research". Electoral Studies, vol. 25, p. $637-663,2006$.

Hogan, R. "Campaign and contextual influences on voter participation in state legislative elections". American Politics Quarterly, vol. 27, no 4, p. 403-433, 1999.

HolBRook, T.; MCCLURG, S. "The mobilization of core supporters: campaigns, turnout, and electoral composition in United States, presidential elections". American Journal of Political Science, vol. 49, no 4, p. 689-703, 2005.

IBGE - Banco de Dados do Sistema IBGE de Recuperação Automática (Sidra) para o Censo Demográfico 2010. Disponível em: <https://sidra.ibge.gov.br/pesquisa/censo-

demografico/demografico-2010/>. Acesso em: 27 fev. 2018.

Inglehart, R.; Welzel, C. Modernização, mudança cultural e democracia. São Paulo: Francis, p. 17$31,2009$.

JACKSON, R. "The mobilization of congressional electorates". Legislative Studies Quarterly, vol. 21, no 3, p. 425-445, 1996.

LIMA JúnIOR, O. B. Democracia e instituições políticas no Brasil dos anos 80. São Paulo: Edições Loyola, 1993.

LIMONGI, F.; MESQUITA, L. "Estratégia partidária e preferência dos eleitores: as eleições municipais em São Paulo entre 1985 e 2004". Novos Estudos Cebrap, vol. 81, p. 49-67, 2008.

MATSUKAKA, J.; PALDA, F. "Voter turnout: how much can we explain?". Public Choice, vol. 98 p. $431-$ 446, 1999.

NicolaU, J. "A participação eleitoral no Brasil." Working Paper CBS-26-2002. University of Oxford Centre for Brazilian Studies, 51f, 2002. Disponível em:

<https://www.academia.edu/3589297/_A_participa\%C3\%A7\%C3\%A3o_eleitoral_no_Brasil_Univeri sty_of_Oxford_Centre_for_Brazilian_Studies_working_paper_series_n._26_2002>.Acesso em: 17 dez. 2017. 
Nicolau, J. História do voto no Brasil. $2^{a}$ ed. Rio de Janeiro: Jorge Zahar Editora, 2004.

PATTIE, C.; JOHNSTON, R. "Voter turnout at the British general election of 1992: rational choice, social standing or political efficacy?". European Journal of Political Research, vol. 33, p. 263-283, 1998.

Peixoto, V.; Goulart, N. "Evolução da competição eleitoral municipal (1996 a 2012) ". Teoria \& Pesquisa, vol. 23, n² 2, p. 41-63, 2014.

PNUD - Banco de Dados do Atlas de Desenvolvimento Humano do Programa das Nações Unidas para o Desenvolvimento (PNUD), 2013. Disponível em: <http://atlasbrasil.org.br/2013/pt/download/>. Acesso em: 31 jul. 2019.

RENNó, L. O dilema do rico: número de candidatos, identificação partidária e accountability nas eleições de 2002 para a Câmara dos Deputados. In: SOARES, G. A. D.; RenNó, L. (orgs.). Reforma política: lições da história recente. Rio de Janeiro: Editora FGV, p. 47-70, 2006.

ReNNó, L. "Desigualdade e informação política: as eleições brasileiras de 2002". Dados, vol. 50, n 4, p. 721-755, 2007.

Ribeiro, E.; BORBA, J.; Silva R. "Comparecimento eleitoral na América Latina: uma análise multinível comparada". Revista de Sociologia e Política, vol. 23, nº 54, p. 91-108, 2015.

SANTOS, W. G. Crise e castigo: partidos e generais na política brasileira. São Paulo: Vértice, 1987. . O cálculo do conflito. Estabilidade e crise na política brasileira. Rio de Janeiro: Iuperj, 2003.

SchwartZman, S. São Paulo e o Estado nacional. São Paulo: Difel, 1975.

SettLe, R.; AbRAmS, B. "The determinants of voter participation: a more general model". Public Choice, vol. 27, p. 81-89, 1976.

SilotTo, G. "Mapeando a competição: padrões de votação em São Paulo entre 2008 e 2016". Revista Parlamento e Sociedade, vol. 5, nº 8, p. 97-123, 2017.

Silva, R. "Comportamento eleitoral na América Latina e no Brasil: em busca dos determinantes das abstenções, votos brancos e votos nulos." Tese de Doutorado em Sociologia Política, Universidade Federal de Santa Catarina, Florianópolis, 2016.

SPECK, B.; CeRvi, E. "Dinheiro, tempo e memória eleitoral: os mecanismos que levam ao voto nas eleições para prefeito em 2012". Dados, vol. 59, no 1, p. 53-90, 2016.

US CEnSUS BUREAU. Disponível em: <https://www.census.gov/prod/cen2010/briefs/c2010br08.pdf>. Acesso em: 12 fev. 2018.

TSE - Repositório de dados eleitorais do Tribunal Superior Eleitoral. Disponível em: $<$ http://www.tse.jus.br/eleitor-e-eleicoes/estatisticas/repositorio-de-dados-eleitorais-1/repositoriode-dados-eleitorais>. Acesso em: 10 dez. 2017.

Wattenberg, M. The decline of party mobilization. In: Dalton, R. J.; Wattenberg, M. P. (eds.). Parties without partisans. Oxford: Oxford Press, p. 64-76, 2000.

Zucco, C.; Nicolau, J. "Trading old errors for new errors? The impact of electronic voting technology on party label votes in Brazil". Electoral Studies, vol. 43, p. 10-20, 2016. 


\begin{abstract}
Apêndice - Estimadores de sete modelos diferentes inspirados na literatura para explicar a porcentagem de comparecimento e votos válidos sobre o eleitorado apto nas eleições para prefeito em 2012
\end{abstract}

Tabela 1

Coeficientes das variáveis de interesse de sete modelos de regressão linear simples para explicar a porcentagem de comparecimento às urnas sobre o eleitorado apto nas eleições para prefeito em 2012

\begin{tabular}{|c|c|c|c|c|c|}
\hline Variáveis & $\begin{array}{c}(1) \\
\text { Settle e } \\
\text { Adams } \\
(1976)\end{array}$ & $\begin{array}{c}(2) \\
\text { Cox e } \\
\text { Munger } \\
(1989)\end{array}$ & $\begin{array}{c}\text { (3) } \\
\text { Matsukaka } \\
\text { e Palda } \\
(1999)\end{array}$ & $\begin{array}{c}(4) \\
\text { Jackson } \\
(1996)\end{array}$ & $\begin{array}{c}(5) \\
\text { Francia e } \\
\text { Hoolbrook } \\
(2004) \\
\end{array}$ \\
\hline Margem de vitória bruta & & $\begin{array}{c}4,44 \mathrm{e}-05^{* * *} \\
(6,68 \mathrm{e}-06)\end{array}$ & & $\begin{array}{c}2,66 \mathrm{e}-05^{* * *} \\
(6,74 \mathrm{e}-06)\end{array}$ & \\
\hline Quadrado da margem de vitória bruta & & $\begin{array}{c}-0 * * * \\
(0)\end{array}$ & & $\begin{array}{c}-0 * * \\
(0) \\
\end{array}$ & \\
\hline $\begin{array}{l}\% \text { da margem de vitória sobre o total de } \\
\text { votos válidos }\end{array}$ & $\begin{array}{c}-0,0408 * * * \\
(0,00604)\end{array}$ & $\begin{array}{c}-0,0493 * * * \\
(0,00620)\end{array}$ & & & $\begin{array}{c}-0,0408 * * * \\
(0,00604)\end{array}$ \\
\hline $\begin{array}{l}\text { \% da margem de vitória de Matsukaka e } \\
\text { Palda }\end{array}$ & & & $\begin{array}{c}-0,0357 * * * \\
(0,00545)\end{array}$ & & \\
\hline Gastos de campanha per capita ( $\mathrm{R} \$ 2012)$ & $\begin{array}{l}0,0580 * * * \\
(0,00501)\end{array}$ & $\begin{array}{l}0,103 * * * \\
(0,00960) \\
\end{array}$ & $\begin{array}{c}0,0582 * * * \\
(0,00501) \\
\end{array}$ & & $\begin{array}{l}0,0580 * * * \\
(0,00501) \\
\end{array}$ \\
\hline $\begin{array}{l}\text { Quadrado dos gastos de campanha per } \\
\text { capita }\end{array}$ & & $\begin{array}{c}-0,000541 * * * \\
(9,51 \mathrm{e}-05)\end{array}$ & & & \\
\hline Log dos gastos de campanha per capita & & & & $\begin{array}{c}1,488 * * * \\
(0,103)\end{array}$ & \\
\hline Número efetivo de partidos & $\begin{array}{c}-5,286 * * * \\
(1,025)\end{array}$ & $\begin{array}{c}-5,352 * * * \\
(1,001)\end{array}$ & $\begin{array}{c}-4,765 * * * \\
(1,003)\end{array}$ & $\begin{array}{c}-2,313 * * \\
(1,007)\end{array}$ & $\begin{array}{c}-5,286 * * * \\
(1,025)\end{array}$ \\
\hline Quadrado do número efetivo de partidos & $\begin{array}{c}0,776 * * * \\
(0,185)\end{array}$ & $\begin{array}{c}0,785^{* * *} \\
(0,180)\end{array}$ & $\begin{array}{c}0,704 * * * \\
(0,183)\end{array}$ & $\begin{array}{c}0,305 \\
(0,188)\end{array}$ & $\begin{array}{c}0,776 * * * \\
(0,185)\end{array}$ \\
\hline Eleição com candidato único & $\begin{array}{l}-0,582 \\
(0,654) \\
\end{array}$ & $\begin{array}{c}0,266 \\
(0,668) \\
\end{array}$ & $\begin{array}{l}-0,726 \\
(0,649) \\
\end{array}$ & $\begin{array}{c}-1,537 * * \\
(0,612) \\
\end{array}$ & $\begin{array}{l}-0,582 \\
(0,654) \\
\end{array}$ \\
\hline Eleição com candidato à reeleição & $\begin{array}{l}0,0928 \\
(0,129)\end{array}$ & $\begin{array}{l}0,0942 \\
(0,127)\end{array}$ & $\begin{array}{c}0,0924 \\
(0,129)\end{array}$ & $\begin{array}{c}0,117 \\
(0,128)\end{array}$ & $\begin{array}{c}0,0928 \\
(0,129)\end{array}$ \\
\hline Eleição de segundo turno & $\begin{array}{c}-0,342 \\
(0,656)\end{array}$ & $\begin{array}{l}-1,042 * \\
(0,609)\end{array}$ & $\begin{array}{c}-0,522 \\
(0,657)\end{array}$ & $\begin{array}{c}-0,848 \\
(0,645)\end{array}$ & $\begin{array}{c}-0,342 \\
(0,656)\end{array}$ \\
\hline $\mathrm{N}$ & 4.455 & 4.455 & 4.455 & 4.455 & 4.455 \\
\hline R-quadrado & 0,404 & 0,416 & 0,404 & 0,409 & 0,404 \\
\hline
\end{tabular}

Fonte: Elaboração própria com dados do TSE, IBGE e Atlas do Desenvolvimento Humano do PNUD.

Nota: Erros-padrão robustos entre parênteses. $* * * p<0,01, * * p<0,05, * p<0,1$. Coeficientes das variáveis de competição da eleição proporcional, das variáveis demográficas, dos controles para região e do termo constante foram omitidos por economia de espaço. A média da margem de vitória bruta é 3.289 votos, com desvio-padrão de 23.943. A porcentagem da margem de vitória inspirada em Matsukaka e Palda (1999) é calculada como: margem de vitória bruta/(votação do primeiro colocado + votação do segundo colocado)*100. A média da porcentagem de margem de vitória inspirada em Matsukaka e Palda é 16,5, com desvio-padrão de 18,4. 
Tabela 2

Coeficientes das variáveis de interesse de sete modelos de regressão linear simples para explicar a porcentagem de votos válidos sobre o eleitorado apto nas eleições para prefeito em 2012

\begin{tabular}{|c|c|c|c|c|c|}
\hline Variáveis & $\begin{array}{c}(1) \\
\text { Settle e } \\
\text { Adams } \\
(1976)\end{array}$ & $\begin{array}{c}(2) \\
\text { Cox e } \\
\text { Munger } \\
\text { (1989) }\end{array}$ & $\begin{array}{c}\text { (3) } \\
\text { Matsukaka e } \\
\text { Palda } \\
\text { (1999) }\end{array}$ & $\begin{array}{c}(4) \\
\text { Jackson } \\
(1996)\end{array}$ & $\begin{array}{c}\text { (5) } \\
\text { Francia e } \\
\text { Hoolbrook } \\
(2004)\end{array}$ \\
\hline Margem de vitória bruta & & $\begin{array}{c}5,52 \mathrm{e}-05^{* * *} \\
(7,15 \mathrm{e}-06)\end{array}$ & & $\begin{array}{c}2,01 e-05 * * \\
(9,18 e-06)\end{array}$ & \\
\hline Quadrado da margem de vitória bruta & & $\begin{array}{c}-0 * * * \\
(0)\end{array}$ & & $\begin{array}{c}-0 \\
(0)\end{array}$ & \\
\hline $\begin{array}{l}\text { \% da margem de vitória sobre o total } \\
\text { de votos válidos }\end{array}$ & $\begin{array}{c}-0,0863 * * * \\
(0,00893)\end{array}$ & $\begin{array}{c}-0,0968 * * * \\
(0,00919)\end{array}$ & & & $\begin{array}{c}-0,0863 * * * \\
(0,00893)\end{array}$ \\
\hline $\begin{array}{l}\text { \% da margem de vitória de } \\
\text { Matsukaka e Palda }\end{array}$ & & & $\begin{array}{c}-0,0759 * * * \\
(0,00797) \\
\end{array}$ & & \\
\hline $\begin{array}{l}\text { Gastos de campanha per capita ( } \mathrm{R} \$ \\
\text { 2012) }\end{array}$ & $\begin{array}{l}0,0638 * * * \\
(0,00562)\end{array}$ & $\begin{array}{l}0,119 * * * \\
(0,0109)\end{array}$ & $\begin{array}{l}0,0641 * * * \\
(0,00561)\end{array}$ & & $\begin{array}{r}0,0638 * * * \\
(0,00562)\end{array}$ \\
\hline $\begin{array}{l}\text { Quadrado dos gastos de campanha } \\
\text { per capita }\end{array}$ & & $\begin{array}{c}-0,000652 * * * \\
(0,000101)\end{array}$ & & & \\
\hline $\begin{array}{l}\text { Log dos gastos de campanha per } \\
\text { capita }\end{array}$ & & & & $\begin{array}{c}1,846 * * * \\
(0,124)\end{array}$ & \\
\hline Número efetivo de partidos & $\begin{array}{c}-3,231 * * \\
(1,449) \\
\end{array}$ & $\begin{array}{c}-3,286 * * \\
(1,422)\end{array}$ & $\begin{array}{l}-2,150 \\
(1,500)\end{array}$ & $\begin{array}{c}2,670 \\
(1,973)\end{array}$ & $\begin{array}{c}-3,231 * * \\
(1,449)\end{array}$ \\
\hline $\begin{array}{l}\text { Quadrado do número efetivo de } \\
\text { partidos }\end{array}$ & $\begin{array}{c}0,395 \\
(0,264) \\
\end{array}$ & $\begin{array}{c}0,402 \\
(0,258) \\
\end{array}$ & $\begin{array}{c}0,245 \\
(0,273) \\
\end{array}$ & $\begin{array}{l}-0,537 \\
(0,358) \\
\end{array}$ & $\begin{array}{c}0,395 \\
(0,264) \\
\end{array}$ \\
\hline Eleição com candidato único & $\begin{array}{c}-13,75 * * * \\
(1,431)\end{array}$ & $\begin{array}{c}-12,70 * * * \\
(1,435) \\
\end{array}$ & $\begin{array}{c}-14,04 * * * \\
(1,420)\end{array}$ & $\begin{array}{c}-16,73 * * * \\
(1,300)\end{array}$ & $\begin{array}{c}-13,75 * * * \\
(1,431) \\
\end{array}$ \\
\hline Eleição com candidato à reeleição & $\begin{array}{r}-0,0503 \\
(0,147)\end{array}$ & $\begin{array}{r}-0,0509 \\
(0,145)\end{array}$ & $\begin{array}{l}-0,0511 \\
(0,147)\end{array}$ & $\begin{array}{l}-0,0361 \\
(0,148) \\
\end{array}$ & $\begin{array}{r}-0,0503 \\
(0,147)\end{array}$ \\
\hline Eleição de segundo turno & $\begin{array}{l}1,691^{*} \\
(0,915) \\
\end{array}$ & $\begin{array}{c}0,875 \\
(0,851) \\
\end{array}$ & $\begin{array}{c}1,308 \\
(0,917) \\
\end{array}$ & $\begin{array}{c}1,184 \\
(0,930) \\
\end{array}$ & $\begin{array}{l}1,691 * \\
(0,915) \\
\end{array}$ \\
\hline $\mathrm{N}$ & 4.455 & 4.455 & 4.455 & 4.455 & 4.455 \\
\hline R-quadrado & 0,433 & 0,436 & 0,431 & 0,413 & 0,433 \\
\hline
\end{tabular}

Fonte: Elaboração própria com dados do TSE, IBGE e Atlas do Desenvolvimento Humano do PNUD.

Nota: Erros-padrão robustos entre parênteses. $* * * \mathrm{p}<0,01, * * \mathrm{p}<0,05, * \mathrm{p}<0,1$. Coeficientes das variáveis de competição da eleição proporcional, das variáveis demográficas, dos controles para região e do termo constante foram omitidos por economia de espaço. A média da margem de vitória bruta é 3.289 votos, com desvio-padrão de 23.943. A porcentagem da margem de vitória inspirada em Matsukaka e Palda (1999) é calculada como: margem de vitória bruta/(votação do primeiro colocado + votação do segundo colocado)*100. A média da porcentagem de margem de vitória inspirada em Matsukaka e Palda é 16,5, com desvio-padrão de 18,4 . 


\begin{abstract}
Competition, campaign spending and electoral fragmentation effects on voter turnout and valid votes in Brazilian local elections in 2012

This article investigates factors associated with the levels of voter turnout, in particular, contextual political variables. The argument is that with the weakening of enduring constraints, such as sociodemographic and sociopsychological, we must consider the short-term effect of the conjuncture on electoral participation. The study of this effect is still incipient in Brazil and Latin America. The initial expectation was that competition, campaign spending, and fragmentation were positively associated with aggregate voter turnout. This hypothesis was tested using multivariate linear models in the mayoral elections of 2012. The results confirm this hypothesis in relation to competition and campaign expenditures, with even more force on valid votes compared to attendance itself. However, the results point to a negative effect of fragmentation.
\end{abstract}

Keywords: voter turnout; electoral competition; campaign spending; electoral fragmentation; Brazil

\title{
Resumen
}

Efectos de competencia, gastos de campaña y fragmentación electoral sobre participación y votos válidos en las elecciones municipales brasileñas en 2012

Este artículo investiga factores asociados a los niveles de participación electoral, en particular, variables políticas contextuales. El argumento es que, con el debilitamiento de condicionantes duraderos, como los sociodemográficos y los sociopsicológicos, debemos atentar al efecto de corto plazo de la coyuntura sobre la participación electoral. El estudio de ese efecto aún es incipiente en Brasil y en América Latina. La expectativa inicial era que la competencia, los gastos de campaña y la fragmentación estuvieran asociados positivamente con la participación electoral agregada. Esta hipótesis fue probada por medio de modelos lineales multivariados en las elecciones para alcalde de 2012. Los resultados confirman esa hipótesis en relación a la competencia y los gastos de campaña, con aún más fuerza sobre los votos válidos si se comparan a la comparecencia en sí. Sin embargo, los resultados apuntan a un efecto negativo de la fragmentación.

Palabras clave: participación electoral; competencia electoral; gastos de campaña; fragmentación electoral; Brasil

\section{Résumé}

Effets de la concurrence, dépenses de campagne et fragmentation électorale sur la participation et votes valides aux élections municipales brésiliennes en 2012

Cet article examine les facteurs associés aux niveaux de participation électorale, en particulier les variables politiques contextuelles. L'argument est que, avec l'affaiblissement des contraintes persistantes, telles que sociodémographiques et sociopsychologiques, nous devons prendre en compte l'effet à court terme de la conjoncture sur la participation électorale. L'étude de cet effet est encore à ses débuts au Brésil et en Amérique Latine. L'attente initiale était que la concurrence, les dépenses de campagne et la fragmentation étaient positivement associées au taux de participation global. Cette hypothèse a été testée à l'aide de modèles linéaires multivariés lors de l'élection des maires de 2012. Les résultats confirment cette hypothèse en ce qui concerne la concurrence et les dépenses liées à la campagne, avec encore plus de force sur les votes valides par rapport à la participation elle-même. Cependant, les résultats indiquent un effet négatif de la fragmentation.

Mots-clés: participation électorale; concurrence électorale; dépenses de campagne; fragmentation électorale; Brésil

Artigo submetido à publicação em 25 de maio de 2018. Versão final aprovada em 15 de julho de 2019.

Opinião Pública adota a licença Creative Commons CC-BY. 